OPEN ACCESS

Edited by:

Ivan Dikic,

Goethe University Frankfurt, Germany

Reviewed by:

Parvin Mehdipour

Tehran University of Medical

Sciences, Iran

Stefan Jentsch,

Max Planck Society, Germany

*Correspondence:

Thorsten Hoppe

thorsten.hoppe@uni-koeln.de

Specialty section:

This article was submitted to

Cancer Genetics,

a section of the journal

Frontiers in Genetics

Received: 25 February 2016 Accepted: 16 April 2016

Published: 03 May 2016

Citation:

Franz A, Ackermann L and Hoppe T (2016) Ring of Change: CDC48/p97

Drives Protein Dynamics

at Chromatin. Front. Genet. 7:73.

doi: 10.3389/fgene.2016.00073

\section{Ring of Change: CDC48/p97 Drives Protein Dynamics at Chromatin}

\author{
André Franz, Leena Ackermann and Thorsten Hoppe*
}

Cologne Excellence Cluster on Cellular Stress Responses in Aging-Associated Diseases, Institute for Genetics, University of Cologne, Cologne, Germany

The dynamic composition of proteins associated with nuclear DNA is a fundamental property of chromosome biology. In the chromatin compartment dedicated protein complexes govern the accurate synthesis and repair of the genomic information and define the state of DNA compaction in vital cellular processes such as chromosome segregation or transcription. Unscheduled or faulty association of protein complexes with DNA has detrimental consequences on genome integrity. Consequently, the association of protein complexes with DNA is remarkably dynamic and can respond rapidly to cellular signaling events, which requires tight spatiotemporal control. In this context, the ring-like AAA+ ATPase CDC48/p97 emerges as a key regulator of protein complexes that are marked with ubiquitin or SUMO. Mechanistically, CDC48/p97 functions as a segregase facilitating the extraction of substrate proteins from the chromatin. As such, CDC48/p97 drives molecular reactions either by directed disassembly or rearrangement of chromatin-bound protein complexes. The importance of this mechanism is reflected by human pathologies linked to p97 mutations, including neurodegenerative disorders, oncogenesis, and premature aging. This review focuses on the recent insights into molecular mechanisms that determine CDC48/p97 function in the chromatin environment, which is particularly relevant for cancer and aging research.

Keywords: CDC48, p97, ubiquitin, SUMO, chromatin, replication, DNA repair

\section{INTRODUCTION}

DNA is the most precious resource of an organism. Its faithful transmission to following generations is of major importance for an individual. Elaborate surveillance mechanisms are required to guard the genome, since large amounts of heterogeneous protein complexes are active at the DNA. Thus, DNA is packaged into highly dynamic chromatin structures for efficient space usage. This involves different histone variants as well as complex protein cohorts that allow for genome function (Misteli, 2007; Cutter and Hayes, 2015). Dependent on cell type, cell cycle phase, environmental cues, or aging status, multisubunit replication and transcription machineries access chromatin and thereby challenge chromosome integrity. In addition, various maintenance and repair mechanisms are active that keep chromatin intact. To ensure genome stability these processes need to be coordinated and tightly controlled in time and space. Within complex protein agglomerations specific proteins have to be recruited or removed to allow a given process to continue. The underlying molecular signaling is predominantly triggered by post-translational modifications (PTMs) of target proteins.

The ATPase CDC48/p97 (also known as VCP in human) is a central factor that integrates recognition, modification and execution of molecular processes mediated by ubiquitin (Ghislain et al., 1996; Meyer et al., 2000; Dai and Li, 2001; Wojcik et al., 2004) or ubiquitin-like molecules 
(Krick et al., 2010; Bandau et al., 2012; den Besten et al., 2012; Nie et al., 2012; Bergink et al., 2013; Køhler et al., 2013, 2015). CDC48/p97 forms homo-hexameric ring-like particles, which undergo extensive conformational changes upon ATP-hydrolysis (Rouiller et al., 2002; Banerjee et al., 2016). These intramolecular changes drive the mechanistic function of CDC48/p97, which is best described as segregase activity (Rape et al., 2001; Braun et al., 2002; Shcherbik and Haines, 2007). While the precise molecular mechanism of substrate handling is controversial (Stolz et al., 2011; Barthelme and Sauer, 2015), cumulating evidence suggests that the ATPdependent conformational rearrangements account for partial unfolding of substrates (Beskow et al., 2009; Godderz et al., 2015; Song et al., 2015), thereby promoting their segregation from multimeric protein assemblies. Following the recognition of target proteins that are marked by ubiquitin, SUMO or both, CDC48/p97 mobilizes the modified substrates from higher order protein complexes, resulting in their inactivation by breaking off the molecular context and/or promoting subsequent proteolytic turnover (Figure 1). The cellular processes that rely on CDC48/p97 segregase activity are diverse (Franz et al., 2014), ranging from degradation of damaged proteins associated with the endoplasmic reticulum (ER, ERAD; Ye et al., 2001; Braun et al., 2002; Jarosch et al., 2002; Rabinovich et al., 2002) or mitochondria (MAD; Heo et al., 2010; Hemion et al., 2014; Fang et al., 2015), ribosome-associated quality control (OssarehNazari et al., 2010; Brandman et al., 2012; Verma et al., 2013) to lipid droplet metabolism (Olzmann et al., 2013), and lysosomal proteolysis (Ren et al., 2008; Ju et al., 2009; Krick et al., 2010; Tresse et al., 2010; Ritz et al., 2011; Buchan et al., 2013). Recently, most attention has been paid to the role of CDC48/p97 in the directed modulation of chromatin-associated protein complexes (Vaz et al., 2013; Dantuma et al., 2014). Herein, fundamental cellular processes such as DNA synthesis and DNA repair as well as transcriptional regulation require CDC48/p97.

Given the growing number of cellular pathways relying on CDC48/p97 function, it appears obvious that independent regulatory mechanisms are required to control the diverse molecular activities. In this context, cofactors provide specificity toward defined CDC48/p97 pathways (Decottignies et al., 2004; Hartmann-Petersen et al., 2004; Medicherla et al., 2004; Schuberth et al., 2004; Wang et al., 2004; Neuber et al., 2005; Park et al., 2005; Richly et al., 2005; Schuberth and Buchberger, 2005; Song et al., 2005; Ritz et al., 2011). Most cofactors interact with CDC48/p97 via conserved binding motifs and provide additional molecular properties that assist in substrate recognition, processing, or regulation of ATPase activity. Substrate recruiting cofactors harbor dedicated domains that recognize conjugated ubiquitin or SUMO, thereby facilitating substrate binding (Kloppsteck et al., 2012; Meyer and Weihl, 2014; Buchberger et al., 2015). Processing cofactors alter the length or topology of ubiquitin or SUMO marks, either by extending (E3-E4 enzymes), shortening (ubiquitin/SUMO hydrolases), or remodeling (also called editing, combined E3E4 and hydrolase activities) the conjugates (Koegl et al., 1999; Hoppe, 2005; Rumpf and Jentsch, 2006; Jentsch and Rumpf, 2007; Kuhlbrodt et al., 2011; Heride et al., 2014).
Other cofactors regulate CDC48/p97 ATPase activity (Trusch et al., 2015; Zhang et al., 2015) thus controlling substrate processing. Cofactors themselves can provide another layer of associated factors (termed accessory factors), thereby defining CDC48/p97 function (Alexandru et al., 2008; Sowa et al., 2009; Balakirev et al., 2015; Raman et al., 2015; Figure 1; Table 1).

The requirement of an organism for CDC48/p97 originates from the variety of processes that depend on its segregase activity. Hence, alterations in CDC48/p97 protein expression or mutations are associated with different diseases including neurodegeneration or premature aging (Partridge et al., 2003; Johnson et al., 2010; Nalbandian et al., 2011; Franz et al., 2014). Moreover, CDC48/p97 overexpression is associated with different cancer types connected with poor prognosis (Fessart et al., 2013). This is intelligible given the diverse chromatin related pathways, like replication or DNA repair that CDC48/p97 is associated with. Since each of these pathways is highly related to tumor formation, p97 constitutes a reasonable target for anticancer therapy (Balch et al., 2008) and first inhibitors are already tested in clinical trials (Deshaies, 2014; Chapman et al., 2015). This review provides an overview on the fundamental role of CDC48/p97 in controlling activity and dynamics of protein complexes at the chromatin. For simplicity, we will refer to spelling of conserved human orthologs throughout the article, unless otherwise stated.

\section{DNA REPLICATION IS DRIVEN BY DYNAMIC COMPOSITION OF PROTEIN COMPLEXES}

The faithful duplication of genomic information during $S$ phase of the cell cycle is a complex biological process involving the highly ordered cascade of numerous replication factors at the chromatin (Masai et al., 2010; Fragkos et al., 2015). DNA synthesis is initiated at origins of replication, which serve as assembly platforms for DNA synthesis factories, termed replisomes. Herein, the concerted activity of origin recognition complex (ORC), CDC6, and CDT1 is required to load the replicative DNA helicase, the Mini-chromosome-maintenance (MCM) complex onto DNA. Together these factors constitute the pre-replicative complex (pre-RC). As pre-RCs do not perform helicase activity yet, pre-RC assembly is considered as licensing of DNA replication. Interestingly, inaccurately assembled preRCs can disassemble from DNA implicating that replication licensing involves quality control mechanisms and iterative loading events (Chen et al., 2007; Xouri et al., 2007; Frigola et al., 2013; Duzdevich et al., 2015). Subsequent to MCM assembly, the pre-RC components are dispensable and consequently inactivated. Origins actively synthesizing DNA are characterized by recruitment of further factors, including CDC45 and the go-ichi-ni-san (GINS) complex (Gambus et al., 2006; Moyer et al., 2006; Ilves et al., 2010). The presence of CDC45 and GINS thus characterizes active replisomes. During ongoing DNA synthesis and particularly close to completion of DNA replication 

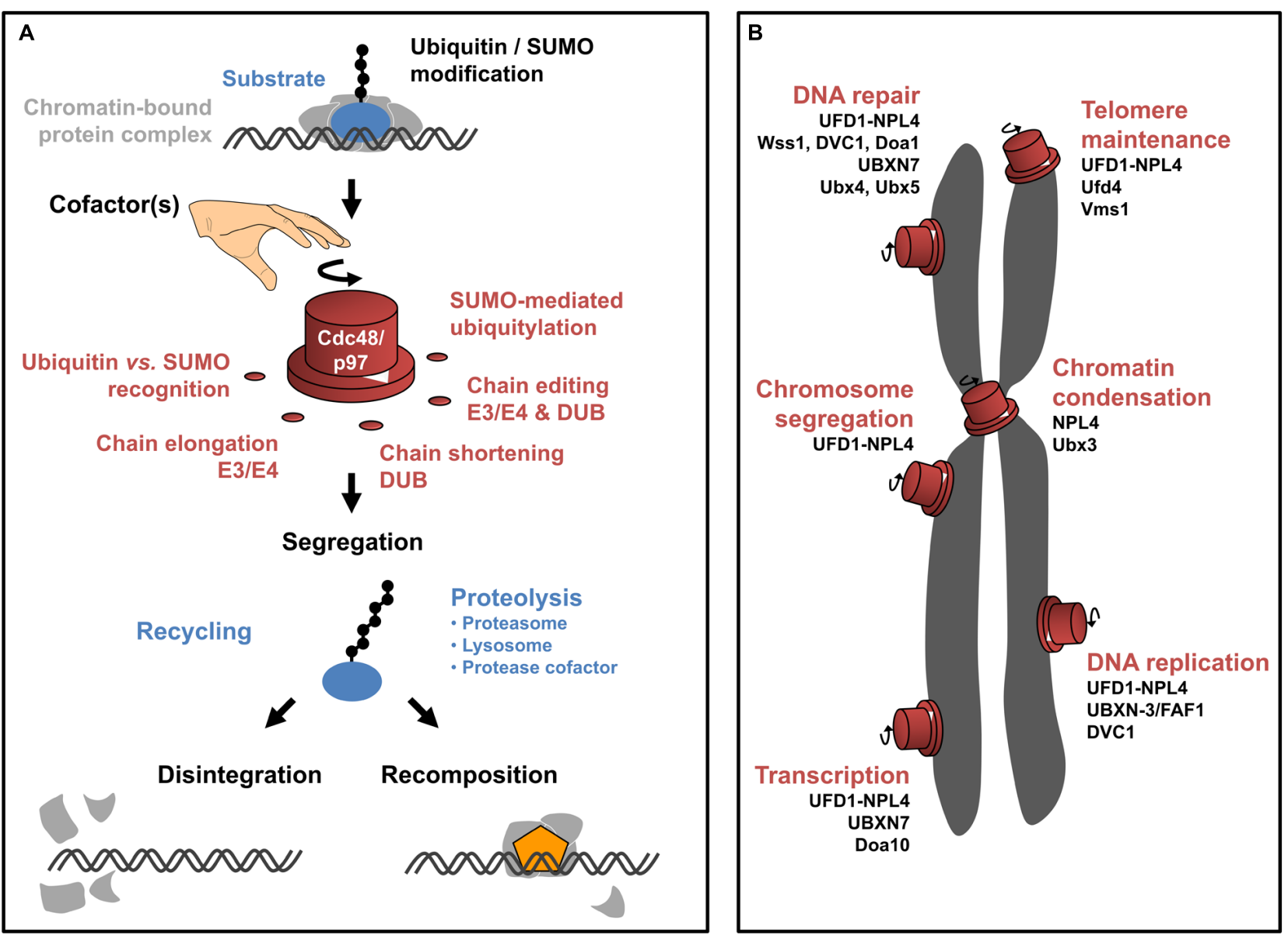

FIGURE 1 | CDC48/p97 function in chromatin-associated processes. (A) Schematic illustration of molecular mechanisms underlying CDC48/p97 activity. CDC48/p97 (red) recognizes chromatin-bound substrates (blue) that are conjugated to ubiquitin or SUMO (black circles). The modification with ubiquitin and SUMO can come in different flavors (exemplified by a chain of molecules). Both molecules can be conjugated as a monomeric moiety or a chain of several molecules. The linkage in between molecules of a ubiquitin chain is variable depending on the internal lysine-(K)-residue used for chain extension (indicated by the angle between ubiquitin molecules of a chain). As such, diverse linkages are capable of defining distinct signaling events (referred to as 'ubiquitin-code'). Moreover, SUMO-dependent ubiquitylation gives rise to hybrid chains. Depending on the exact modification of the substrates, diverse cofactors facilitate substrate recognition and/or processing of the ubiquitin/SUMO modification by extending, removing, or internal remodeling of the chain. This is probably important to define the directionality of the CDC48/p97 reaction. Eventually, CDC48/p97 segregase activity is required to mobilize the substrate from higher order protein complexes (light gray). On one hand the substrate can be recycled, probably involving hydrolysis of the modification. Otherwise, the substrate can be terminally degraded involving the proteasome, lysosome, or proteolytic cofactors. Extraction of the substrate can promote two distinct outcomes. Disintegration of the protein complex can result in its inactivation (bottom left). Alternatively, extraction of the substrate can disclose the binding site of another factor (orange) thus facilitating the directed progression of the reaction (bottom right). (B) Schematic overview of CDC48/p97-dependent pathways in the context of eukaryotic chromosomes (gray). CDC48/p97 (red) possesses molecular switch properties, driving molecular reactions in distinct chromatin-associated processes. The involvement of respective CDC48/p97 cofactors is listed below the indicated pathways.

converging replication factories collide and are considered to require regulated disassembly (Maric et al., 2014; Moreno et al., 2014). These processes exemplify that the composition of replication factories is highly dynamic throughout the regular replication program and, moreover, responsive to genotoxic insults that might threaten genome stability (Sirbu et al., 2013; Alabert et al., 2014; Dungrawala et al., 2015; Raschle et al., 2015). Intriguingly, CDC48/p97 has been shown to be essential for DNA replication in eukaryotes by regulating the abundance of several replication factors at distinct time points (Figure 1; Table 1).

\section{CDC48/p97-mediated Control of DNA Replication Licensing and Fork Progression}

The functional relevance of CDC48/p97 in DNA synthesis was first shown in Caenorhabditis elegans (C. elegans). RNAimediated depletion of CDC48/p97 or the dimeric cofactor UFD1-NPL-4 caused replication defects accompanied with collapsed forks and formation of DNA repair foci (Mouysset et al., 2008). This initial observation of compromised DNA synthesis upon inactivation of the CDC48/p97 $7^{\mathrm{UFD}-1-\mathrm{NPL}-4}$ complex was 
TABLE 1 | CDC48/p97 substrates in the chromatin environment.

Cdc48/p97-dependent process

Substrate(s)

DNA replication

Replication fork progression, G2/M checkpoint

Replication licensing

Replication stress

Replication stress, DNA damage tolerance (DDT)

Replication termination

\section{DNA repair}

Diverse genotoxic insults

Diverse genotoxic insults

DNA damage response (DDR)

DNA-double strand break repair

DNA-double strand break repair

DNA-double strand break repair

DNA-double strand break repair DNA-protein crosslink (DPC)

PCNA-dependent response to UV-light

UV-light induced protein turnover UV-light induced protein turnover UV-light induced protein turnover

UV-light induced protein turnover

\section{Cofact \\ factors}

Top1, a.o.

\section{Transcription}

Histone ubiquitylation

Mating-type switch

Transcriptional inactivation

Transcriptional regulation

Heterochromatin decondensation

Telomere maintenance

Telomerase efficiency

Telomerase efficiency

Sister-chromatid segregation

Anaphase degradation

Chromatin

decondensation/congression

Meiosis

Others

Global analysis n.d.

CDT-1, CDC-45-GINS

$\begin{array}{ll}\text { FANCI, FANCD2 } & \text { DVC1 } \\ \text { Pol }, \text { a.o. } & \text { DVC1 }\end{array}$

MCM7 Dia2

Dia2

SUMO/Ubiquitin-
conjugates
SUMO/Ubiquitin-
conjugates
Top1,
SUMO-conjugates
L3MBTL1

Ufd1, Npl4

Ufd1, Npl4, Rfp1, Pli1

Wss1, Doa1

UFD1, NPL4

SUMO-Rad52

Ufd1

Ubiquitin-(K48)-

conjugates

DNA-PKcs

n.d.

CSB

CDT1, SET8

DDB2, XPC

Rbp1

DVC1

UFD-1, NPL-4, BXN-3/FAF1

C. elegans

S. cerevisiae, $X$. laevis

S. cerevisiae

S. pombe

S. cerevisiae

Mammalian cells,

C. elegans

S. cerevisiae, mammalian cells

UFD1, NPL4

n.d.

Wss1

DVC1, mono-ubiquitylated PCNA

UFD1, UBXN7, CUL4

UFD1, NPL4, a.o.

UFD1, NPL4, UBXN7,

CUL4

Ufd1, Npl4, Ubx4, Ubx5, Cul3

Histone 2B
$\alpha 2$
HIF1 $\alpha$
LexA-VP16, Met4,
R-Smads
CenH3

Ubx3

Ufd1, Npl4, Doa10, a.o. UBXN7, CUL2, VHL Ufd1, Npl4

Ufd1, Npl4

Vms1

Ufd1, Npl4, Ufd4

Est1

n.d.

Ubx4

Aurora-B

Ufd1, Npl4

AIR-2

n.d.
Mammalian cells

Mammalian cells

S. cerevisiae

Mammalian cells

Mammalian cells

Mammalian cells, $X$. leavis

Mammalian cells

S. cerevisiae

S. cerevisiae, mammalian cells

S. cerevisiae

Mammalian cells

S. cerevisiae

A. thaliana

S. cerevisiae

S. cerevisiae

S. cerevisiae

$X$. leavis, mammalian cells

C. elegans
Reference

Lessel et al., 2014

Mouysset et al., 2008;

Franz et al., 2011, 2016

Gibbs-Seymour et al., 2015

Davis et al., 2012;

Mosbech et al., 2012

Maric et al., 2014; Moreno et al., 2014; Maculins et al., 2015

Nie et al., 2012

Køhler et al., 2013

Balakirev et al., 2015

Acs et al., 2011

Bergink et al., 2013

Meerang et al., 2011

Jiang et al., 2013

Stingele et al., 2014

Centore et al., 2012

He et al., 2016

Raman et al., 2011

Puumalainen et al., 2014

Verma et al., 2011

Bonizec et al., 2014

Wilcox and Laney, 2009

Alexandru et al., 2008

Ndoja et al., 2014

Merai et al., 2014

Baek et al., 2012

Lin et al., 2015

The table lists the identified chromatin-associated substrates of CDC48/p97, sorted by their functional relevance in indicated cellular processes. In addition, the involvement of cofactors and/or accessory factors is displayed along with the experimental system that was used in the respective publication (a.o. and others, n.d. not determined). 
further addressed in a follow-up study, identifying chromatinassociated CDT-1 is the primary substrate (Franz et al., 2011; Raman et al., 2011). Herein, the abundance of the licensing factor CDT-1 on chromatin relies on CDC48/p97 activity during initiation of DNA replication (Franz et al., 2011). In addition, CDT-1 stabilization on mitotic chromatin (correlating to G1 phase), coincides with chromatin-retention of CDC-45 and the GINS complex (Franz et al., 2011). A genetic interaction screen identified the UBX-domain protein UBXN-3 as a specialized cofactor enhancing substrate recognition by CDC48/p97 during DNA replication (Franz et al., 2016). Indeed, in vivo and in vitro protein interaction analysis confirmed that UBXN-3 provides substrate recognition toward CDT-1 and other ubiquitylated proteins (Franz et al., 2016). Analysis of individual replication forks in human cell lines revealed that siRNA-mediated depletion of the human ortholog FAF1 causes severely impaired replication fork progression associated with elevated frequency of replication fork stalling and firing of dormant origins. In fact, CDT1 protein appears to be the primary target of $\mathrm{CDC} 48 / \mathrm{p} 97^{\mathrm{FAF} 1}$ also in human cells, as indicated by genetic suppression of replication defects upon codepletion and in vivo binding studies (Franz et al., 2016). Taken together, CDC48/p97 UFD1-NPL4, in complex with the substrate recognition module UBXN-3/FAF1, controls replication fork progression by restraining the abundance of CDT1 during replication licensing.

It should be noted that the regulatory mechanism depicted above is specific to the G1 phase of the cell cycle (Ballabeni et al., 2004; Franz et al., 2011). In contrast CDT1 protein levels are also under control during the ensuing $\mathrm{S}$ phase, involving PCNA and Cullin-based E3 ligases (Zhong et al., 2003; Arias and Walter, 2007; Havens and Walter, 2009; Sugimoto et al., 2009; Coleman et al., 2015). S phase degradation of CDT1 is considered as fundamental in preventing over-replication in one cell cycle as well as avoidance of chromosomal rearrangements (Davidson et al., 2006; Tatsumi et al., 2006). In response to DNA damage, CDT1 chromatin extraction and degradation also involves CDC48/p97 activity (Hu et al., 2004; Jin et al., 2006; Raman et al., 2011). In contrast to the licensing factors ORC and Cdc6, Cdt1 is required for break-induced replication in yeast (Lydeard et al., 2010). The exact requirement of CDT1 and its subsequent inactivation during DNA repair, however, remains elusive.

Interestingly, another thus far unappreciated cofactor of CDC48/p97 has attracted attention as a critical regulator in cellular pathways ensuring genome integrity (Stingele et al., 2015). Two studies could show that mutations in DVC1 [also called Spartan (SPRTN) or C1orf124 in humans, functionally related to Wss1 in Saccharomyces cerevisiae] are causative for genome instability phenotypes cumulating in hepatocellular carcinoma and progeria (Lessel et al., 2014; Maskey et al., 2014; Figure 1; Table 1). Patient cells expressing dysfunctional DVC1 show hallmarks of genomic instability, which is accompanied by aberrant replication fork velocity along with excessive replication stress. Furthermore, patient cell lines escape the cell cycle control by $\mathrm{G} 2 / \mathrm{M}$ checkpoint, which usually halts the transition into mitosis until damage is repaired. Importantly, human cells exclusively expressing disease-related DVC1 mutations phenocopy the observations made in primary cells (Lessel et al., 2014). Identification of respective target substrates will decipher, which aspect of DNA replication is controlled by DVC1. Indeed DVC1 could be shown to colocalize with DNA replication factories in synchronized but otherwise untreated mammalian cells (Davis et al., 2012). Its functional relevance, however, became particularly important upon treatment with various types of genotoxic agents, which triggered the DVC1dependent recruitment of CDC48/p97 to sites of DNA damage (Centore et al., 2012; Davis et al., 2012; Mosbech et al., 2012). Intriguing insights into the mechanistic function of DVC1's cognate Wss1 in chromatin-associated protein degradation have recently been reported in the context of replication-coupled DNA repair (Stingele et al., 2014; Balakirev et al., 2015). Herein, Wss1 protease was identified to specifically mediate the processing of DNA-protein crosslinks (DPC) in a thus far overlooked repair pathway that presumably also underlies genome instability in DVC1 mutant cells (Figure 1; Table 1 and references therein). Accordingly, disease-causing mutations locate in the domain encoding the predicted DVC1 protease (SprT) domain (Lessel et al., 2014); however, a chromatin-directed protease activity of DVC1 awaits affirmation. The mechanistic details of DPC-repair will be discussed in the respective paragraph on DNA-repair pathways.

\section{Termination of DNA Replication Requires CDC48/p97 Activity}

Until recently, the molecular mechanisms underlying the termination of DNA replication in metazoans was only scarcely described (Dewar et al., 2015). Thus, the identification of CDC48/p97 in the release of the MCM helicase in complex with CDC45 and GINS (collectively termed CMG complex) at sites of replication termination was astonishing (Maric et al., 2014; Moreno et al., 2014). Yeast cells or Xenopus egg extracts that are depleted for CDC48/p97 are defective in the disassembly of the CMG complex at the end of the cell cycle when replication forks collide with high frequency. Both studies show that selective poly(K48)-ubiquitylation of the MCM7 subunit is required to trigger CMG release (Maric et al., 2014; Moreno et al., 2014). Interfering with polyubiquitylation as well as CDC48/p97 activity, result in accumulation of DNA structures comparable to pharmacological inhibition of termination (Moreno et al., 2014). Moreover, ubiquitylation of MCM7 depends on active progression through S phase (Maric et al., 2014; Moreno et al., 2014). In conclusion, DNA replication requires CDC48/p97 activity to terminate DNA synthesis by unloading of active CMG complexes.

Comparing CDC48/p97-dependent regulation of replication licensing with termination of replication leaves open questions to be addressed. Moreno et al. (2014) used an experimental system in Xenopus egg extracts that affects polyubiquitylation in progressing $S$ phase, thus allowing exclusive analysis of replication termination. In $S$. cerevisiae, the licensing factor Cdt1 is not regulated via proteolysis, but nuclear export, pointing at distinct regulatory mechanisms between unicellular fungi and metazoans (Tanaka and Diffley, 2002; Feng and Kipreos, 2003; Kim and Kipreos, 2007). What are the respective cofactors that 
define CDC48/p97 specificity toward replication termination? In yeast, the ligase complex $\mathrm{SCF}^{\mathrm{Dia} 2}$ catalyzes the ubiquitylation of MCM7 and thus provides the signal for CMG disassembly (Maric et al., 2014; Maculins et al., 2015). The substrate recognition factor Dia2, however, is not obviously conserved outside of the fungi kingdom. In Xenopus, release of CMG complex has been linked to the E3 ligase BRCA1, however, is supposed to be specific to stalled replisomes but not termination (Long et al., 2014; Dewar et al., 2015). As such, CDC48/p97-dependent CMG release might be considered as a combined phenotype: aberrant licensing causing stalled forks, in turn requiring active CMG unloading. In C. elegans and Xenopus egg extracts, CDC48/p97 is linked to the release of CDC-45 and GINS after $S$ phase is completed (Franz et al., 2011, 2016). Herein, CDC48/p97 cooperates with the cofactors UFD-1-NPL-4 and $\mathrm{UBXN}-3 / \mathrm{FAF} 1$, however, neither the depletion of $u f d-1, n p l-4$, nor $u b x n-3$ resulted in persistent chromatin-association of MCM subunits (Franz et al., 2016). These observations support the idea that CMG disassembly is more complex involving dedicated CDC48/p97 cofactors separately targeting MCM or CDC45GINS. It has been speculated that a ring-shaped GINS molecule embraces DNA (Kubota et al., 2003; Boskovic et al., 2007), thus chromatin release might be regulated independently from MCM. Alternatively, CMG disassembly might be differentially regulated in invertebrates and vertebrates. In human cells, unloading of MCM complexes has been linked to the deubiquitylating activity of USP7 (Jagannathan et al., 2014), implicating that regulated MCM release might involve editing of ubiquitin chains. Whether USP7 activity is indeed coordinated by CDC48/p97 remains to be elucidated.

\section{PROTEIN DYNAMICS AT SITES OF DNA REPAIR}

DNA damage poses a major threat to cells. Besides defects in replication, additional intrinsic incidents may threaten chromatin integrity. Hence damage may originate from hydrolytic reactions or reactive oxygen species (ROS). However, also extrinsic and highly carcinogenic sources like UV exposure or tobacco products harm DNA. If unrepaired, DNA damage leads to accumulation of mutations or chromosomal aberrations and promotes genome instability, the cause for many diseases including cancer (Jackson and Bartek, 2009; Ciccia and Elledge, 2010). Specific to the damaging agent, the recognition of the damage and the molecular mechanism for its removal are diverse. One unifying feature of all repair pathways, however, is the progression through specific phases of damage recognition, effective repair, and finally resolution of repair intermediates. The underlying DNA damage response (DDR) triggers the dynamic and hierarchically ordered assembly and disassembly of repair factors on the chromatin (Hoeijmakers, 2001). CDC48/p97 plays a central role in various DNA repair scenarios and specialized cofactors provide mechanistic regulatory insight (Figure 1; Table 1). Please also see latest review articles on this topic (Vaz et al., 2013; Dantuma et al., 2014; Brinkmann et al., 2015; Dantuma and van Attikum, 2016).

\section{CDC48/p97 Activity in Processing of DNA Double Strand Breaks}

The most detrimental DNA lesions are double strand breaks (DSBs) since inadequate fusion of loose ends can give rise to considerable chromosome rearrangements, duplications, or deletions and hence are a severe threat for genome integrity (Hoeijmakers, 2009). Two main pathways known to repair DSBs operate differently. One is comparably simple by ligating the loose ends back together in a reaction called nonhomologous end-joining (NHEJ). The other, termed homologous recombination (HR) is a much more concise pathway, using a homologous template for reestablishing the undamaged state (Hoeijmakers, 2001; San Filippo et al., 2008; Lieber, 2010; Mehta and Haber, 2014; Kowalczykowski, 2015).

CDC48/p97 was first implicated in DNA repair by finding that it gets phosphorylated at $S^{784}$ upon DNA damage induction (Livingstone et al., 2005). Indeed DNA-dependent protein kinase, catalytic subunit (PKcs), one of the kinases mediating this PTM (Livingstone et al., 2005), directly interacts with CDC48/p97 upon ubiquitylation (Jiang et al., 2013). DNAPKcs associates with a heterodimer of Ku70-Ku80 at DSBs and initiates NHEJ (Wang et al., 1994; Davis et al., 2014). CDC48/p97 acts here to restrict DNA PKcs occupancy on DNA by handing it over to proteasomal turnover. In this glioma cell model, loss of CDC48/p97 improves repair efficiency temporally (Jiang et al., 2013). Conversely, other studies described an increase in sensitivity toward DNA damage and subsequent genome instability when CDC48/p97 activity is limited (Acs et al., 2011; Meerang et al., 2011; Raman et al., 2011). Upon DNA DSB induction a well-studied signaling cascade is commenced, involving initial phosphorylation steps but subsequent engagement of the ubiquitin and SUMO machinery to establish binding sites for specific signaling proteins like BRCA1 and 53BP1 (Bekker-Jensen and Mailand, 2011; Polo and Jackson, 2011). This process requires tight regulation; however, ubiquitylation does not only serve as a binding platform orchestrating the recruitment of specific interaction partners. Instead also poly-(K48)-linked ubiquitin chains, which trigger proteasomal degradation (Dammer et al., 2011), were identified at DDR sites that strongly accumulate in CDC48/p97 depleted cells (Meerang et al., 2011). This observation indicates the requirement for CDC48/p97 to remove K48-ubiquitylated proteins from break sites and possibly allow recruitment of downstream factors. In fact, loss of CDC48/p97 function seems to have broad impact on recruitment of repair proteins. After treating cells with ionizing irradiation, CDC48/p97 depletion attenuates recruitment of 53BP1, BRCA1, and abolishes loading of RAD51 to repair sites (Meerang et al., 2011). Mechanistically it remained unclear how CDC48/p97 promotes recruitment of downstream proteins. A recent study highlighted that CDC48/p97 specifically enables recruitment of 53BP1 to DSBs induced by micro-irradiation. 53BP1 association with DSBs is dependent on the ubiquitin cascade but does itself not bind to ubiquitin (Botuyan et al., 2006). Here yet again a switch in signaling molecules has to be implemented. 53BP1 binds to H4K20me2, a histone mark that is initially occupied by L3MBTL1 (Min et al., 2007). Upon ubiquitylation, L3MBTL1 is primed for 
extraction by CDC48/p97 together with its cofactors NPL4 and UFD1. Only then 53BP1 is able to bind its designated recruitment site and the repair process can be pursued (Acs et al., 2011). Even though different outcomes of CDC48/p97 activity at damage loci are described, both emphasize the requirement of CDC48/p97 to extract ubiquitylated target proteins from DNA damage signaling sites to facilitate further repair steps.

\section{CDC48/p97 Functions as SUMO-dependent Segregase to Provide Genome Stability}

Aside ubiquitin-conjugates CDC48/p97 and its cofactor UFD1 both recognize SUMOylated target proteins directly (Nie et al., 2012). A functional relevance of CDC48/p97 exclusively targeting SUMO-conjugates was first described in the assembly of downstream effector proteins during DNA repair (Bergink et al., 2013). During HR the essential recombinase RAD51 forms long filaments on the two single stranded loose DNA ends, which enable scanning and approaching the homologous sequence (Holthausen et al., 2010; Forget and Kowalczykowski, 2012). Its DNA association needs to be tightly controlled, since hyperrecombination is highly cytotoxic; at the same time RAD51 is essential for recombination (Tsuzuki et al., 1996; Sonoda et al., 1998; Richardson et al., 2004; Klein, 2008). In yeast, SUMOconjugated Rad52 interacts with and aides Rad51 loading onto DNA when engaged in HR. Interestingly, CDC48/p97 $7^{\text {Ufd1 }}$ has direct binding affinity toward the same SUMOylated lysine on Rad52 hence counterbalancing recombination events mediated by Rad51 (Bergink et al., 2013). This finding highlights a function of CDC48/p97 independent of ubiquitin and implies that competitive binding to SUMO can promote segregation activity.

In addition to minimizing Rad51-Rad52 interaction, CDC48/p97 plays a more global role in the regulation of SUMO-conjugates at the chromatin (Køhler et al., 2015). SUMOylation was established as another layer of regulation at DSB sites that enables thorough repair (Hardeland et al., 2002; Cremona et al., 2012; Jackson and Durocher, 2013). Mutations in SUMO related proteins lead to genomic instability, but again, inappropriate retention of SUMOylated proteins on DNA also impedes accurate repair since recruitment of downstream factors is strongly reduced (Psakhye and Jentsch, 2012). Interestingly, the CDC48/p97 Ufd1-Np14 complex has been implicated in this specific extraction as well. Ufd1 harbors a SUMO interaction motif (SIM) by which it directly binds SUMO (Nie et al., 2012). Additionally, specific ubiquitin ligases target SUMOylated proteins for ubiquitylation (SUMO-targeted ubiquitin ligases: STUbLs). CDC48/p97 together with its cofactors is thus recruited via a dual mechanism consisting of ubiquitin and SUMO, thereby facilitating extraction and possibly degradation of SUMOylated proteins at DNA damage sites (Nie et al., 2012). UFD1 takes an important role as cofactor of $\mathrm{CDC} 48 / \mathrm{p} 97$. In addition to its direct binding to SUMO, a physical as well as functional interaction of Ufd1 with the STUbL Rfp1 (RNF4 ortholog) or the SUMO E3 ligase Pli1 (PIAS1) was shown. The concerted action of these proteins leads to ordered removal of SUMOylated proteins at damage site, again their inappropriate retention by loss of one of the factors entails genomic instability (Køhler et al., 2013). This example nicely highlights CDC48/p97s function as a molecular switch. It provides a platform for a variety of functionally distinct proteins that together lead to precisely coordinated CDC48/p97-dependent chromatin extraction of client proteins (Figure 1; Table 1).

An analogous mechanism was described for DNA repair by the Fanconi anemia pathway. After replication block, Fanconi anemia pathway becomes active to promote fork restart by initiating translesion synthesis and damage removal (Haynes et al., 2015). Two central components, FANCI and FANCD, are SUMOylated upon fork stalling. As described for other SUMOylated proteins, they are targeted for degradation by RNF4 mediated ubiquitylation and subsequent mobilization from DNA by the CDC48/p97 complex (Gibbs-Seymour et al., 2015). Here CDC48/p97 acts jointly with DVC1. Degradation of FANCI and FANCD is impaired in RNF4 mutants, highlighting that in this case ubiquitin binding of the CDC48/p97 $7^{\mathrm{DVC} 1}$ complex is necessary.

\section{Processing of DNA-protein Crosslinks}

Proteins that are crosslinked to DNA or chromatin are a specialized form of chromatin modification, which can arise from metabolic sources or external insults such as reactive aldehydes, UV-light, or catalytic intermediates, e.g., upon Topoisomerase 1 inhibition (Duxin and Walter, 2015; Stingele and Jentsch, 2015; Stingele et al., 2015). DPCs result in stalling of RNA and DNA polymerases and thus impact on a variety of cellular processes. Consequently, DPCs need to be removed in a regulated manner that involves incomplete proteolytic digestion. Subsequently, the processed DPC remnant can be bypassed by a specialized translesion polymerase (Duxin et al., 2014), whereas the DPC remnant itself is considered to be eventually removed by base excision repair. Intriguingly, a DVC1-related protease acts as CDC48/p97 cofactor and harbors protease activity to catalyze DPC processing in yeast (Stingele et al., 2014, 2015; Figure 1; Table 1). Wss 1 protease activity becomes particularly activated upon DNA binding, where it digests DPCs including covalently bound Topoisomerase 1, other chromatin-bound proteins as well as itself for inactivation (Stingele et al., 2014; Balakirev et al., 2015). Interestingly, Wss1 specifically targets SUMOconjugates on chromatin via its SUMO-interaction motif (Mullen et al., 2010; Stingele et al., 2014; Balakirev et al., 2015). In contrast DVC1 is directed toward ubiquitin-conjugates and is linked to the PCNA sliding clamp (Centore et al., 2012; Davis et al., 2012; Juhasz et al., 2012; Mosbech et al., 2012; GibbsSeymour et al., 2015). In case of replication fork stallinginduced extraction of the Fanconi anemia ID complex, the SUMO-dependent ubiquitin E3 ligase RNF4 is central for the underlying signaling (Gibbs-Seymour et al., 2015), supporting the idea that DVC1 regulation in metazoans is multilayered involving both SUMO and ubiquitin. Although a chromatindirected protease activity of DVC1 awaits to be verified, it is feasible that DVC1 and Wss1 represent functional equivalents. This might explain initial observations that DVC1 is required for the removal of translesion polymerase after UV-lesion bypass 
(Centore et al., 2012; Davis et al., 2012; Ghosal et al., 2012; Juhasz et al., 2012; Mosbech et al., 2012; Kim et al., 2013), which is probably linked to attenuated processing of DPCs (Duxin et al., 2014; Duxin and Walter, 2015). Recently, the CDC48 cofactor Doa1 (also known as UFD3 or PLAP) was shown to be present in CDC48/p97Wss1 complexes (Balakirev et al., 2015). In this study, genotoxic stress resulted in nuclear GFP-Wss1 punctae, consistent with the formation of DNA repair foci. This is in line with formation of nuclear DVC1 foci upon exposure to genotoxic stress by HU, UV-light, or laser microirradiation in C. elegans and mammalian cells (Davis et al., 2012; Mosbech et al., 2012). Moreover, GFP-Wss1 translocates to the vacuole upon damage induction, pointing at a putative role of lysosomal degradation in Wss1-mediated DDR involving the Doal cofactor.

To date, the mechanistic role of CDC48/p97 in Wss1dependent DDR is still obscure. Upon genotoxic insults DVC1/Wss1 recruits CDC48/p97 to the damaged site, pointing at an adaptor-like function promoting segregase activity (Centore et al., 2012; Davis et al., 2012; Mosbech et al., 2012; GibbsSeymour et al., 2015). It appears likely, that DVC1/Wss1's intrinsic protease activity is particularly important in cases of DPCs, when CDC48/p97 segregase is not capable of processing the substrate due to covalent linkage to the DNA (Stingele et al., 2014). The observation that Wss1 harbors SUMO-ligase (Balakirev et al., 2015) as well as isopeptidase activity (Mullen et al., 2010) suggests that Wss1 function might include additional layers of regulation.

\section{CDC48/p97 Dependent Extraction in UV Induced DNA Damage Repair}

Not only replication block but also obstruction of transcription poses a major threat to DNA. Frequent sources of transcription fork stalling are bulky UV lesions (Mullenders, 2015). To avoid stalling of forks, the cell probes constantly for these helix distortions via the global genome nucleotide excision repair (GG-NER) pathway that is active on both DNA templates. Here, XPC together with UV-DDB complex (UV-DNA damage binding protein) consisting of DDB1 and DDB2 detect lesions and initiate repair (Hoogstraten et al., 2008; Marteijn et al., 2014). To proceed with the excision reaction, these factors need to be removed from chromatin. CDC48/p97 in complex with NPL4-UFD1 and UBXD7 regulates the chromatin association of $\mathrm{XPC}$ and DDB2. Ubiquitin dependent extraction by CDC48/p97 allows their proteasomal degradation. Depletion of CDC48/p97 promotes retention of those factors and ultimately leads to genomic aberrations (Puumalainen et al., 2014). In contrast, the DUB USP7 was identified to counteract CDC48/p97 dependent extraction of XPC. It shortens the ubiquitin chain on the target protein, thereby removing the signal for extraction and possible degradation (He et al., 2014).

In case RNA Polymerase II (RNA Pol II) encounters such lesions on the actively transcribed strand, transcription coupled NER (TC-NER) is initiated (Spivak and Ganesan, 2014). During TC-NER CSB is involved in repair initiation (Fousteri et al., 2006; Anindya et al., 2010). Similar to XPC and DDB2 degradation in GG-NER, CDC48/p97-dependent proteolysis of CSB is required to facilitate progression of DNA repair upon UV-irradiation
(He et al., 2016). To this end, CSB removal from chromatin is mediated by the cofactors UFD1 and UBXN7 (He et al., 2016). Both sub-pathways, GG-NER and TC-NER have different initiation signals, but merge into one mutual pathway after initial processing. When the injured DNA is excised the gap of 22-30 nucleotides needs to be sealed again. This is accomplished by replication proteins, including PCNA, a DNA polymerase, and subsequent ligation (Marteijn et al., 2014; Mullenders, 2015). In this context, CDC48/p97 is associated with removal and ensuing proteasomal degradation of CDT1 and histone methyl transferase SET8 (Raman et al., 2011). Chromatin association of the two proteins is tightly regulated not only during replication but also upon repair to avoid unscheduled replication initiation (Senga et al., 2006). Binding to the PCNA interaction protein motif degron (PIP degron) of PCNA generally primes target proteins for ubiquitylation by CRL4 ${ }^{\text {Cdt2 }}$ (Havens and Walter, 2009). Hence, after UV damage, CDC48/p97 extracts ubiquitylated CDT1 and SET8 from damaged chromatin and sends both substrates for destruction by the proteasome (Raman et al., 2011).

Normally the cell favors preserving RNA Pol II upon stalling; this is achieved by RNA Pol II backtracking, which allows repair proteins to access the lesion (Epshtein et al., 2014). As a last resort, when NER cannot be executed, RNA Pol II is removed and degraded to prevent even more severe damage (Wilson et al., 2013). Upon UV irradiation, degradation of the largest subunit of RNA Pol II Rpb1 is facilitated by ubiquitin dependent extraction. Herein, CDC48/p97 cooperates with its cofactors Ufd1 and Npl4, as well as with Ubx5 (UBXN7; Verma et al., 2011), a cofactor that is also associated with NER dependent protein extraction in humans.

\section{ADDITIONAL FUNCTION OF CDC48/p97 IN CHROMOSOME BIOLOGY}

In contrast to the load of DNA damage another determinant of cellular aging is the shortening of chromosome ends, the telomeres, with consecutive cell divisions. Interestingly, a function of CDC48/p97 in the regulation of telomere length has recently been proposed based on the identification of Cdc13 and Est1 as substrate proteins (Baek et al., 2012; Lin et al., 2015; Figure 1; Table 1). Both, Cdc13 and Est1 are key regulators of telomere replication in yeast. Baek et al. (2012) showed that CDC48/p97 cooperates with the Vms1 (ANKZF1) cofactor in the proteolytic turnover of Cdc13. Interestingly, Cdc13 destruction appears to involve both proteolytic routes, the proteasome and the lysosome. In contrast Lin et al. (2015) propose that CDC48/p97 together with Ufd1-Npl4 and the ubiquitin E3 ligase Ufd4 (TRIP12) cooperate to adjust telomere length by limiting the abundance of mono-ubiquitylated Est1. Consequently, CDC48/p97 inactivation results in shortened telomeres, presumably due to inefficient telomerase upon Cdc13 and Est1 accumulation.

In addition to DNA synthesis and repair pathways, CDC48/p97 plays pivotal roles during sister-chromatid segregation. Faulty segregation of chromatids during mitosis is a significant source of copy number variations, large 
chromosomal aberrations, or chromosome destruction. In fact, a key regulator of mitosis, the kinase Aurora-B, was the first chromatin-associated substrate of CDC48/p97 to be identified (Ramadan et al., 2007; Figure 1; Table 1). Interestingly, CDC48/p97 Ufd1-Npl4 restricts Aurora-B activity to promote chromosome congression or chromatin relaxation at distinct time-points during mitosis, as well as chromosome segregation during meiotic division (Ramadan et al., 2007; Dobrynin et al., 2011; Sasagawa et al., 2012). The involvement of cofactors in the regulation of Aurora-B during meiosis I, however, remains to be defined. In yeast cells, CDC48/p97 and its cofactor Ubx4 are involved in the nuclear distribution of proteasomes, thus defining protein degradation during anaphase (Chien and Chen, 2013), implicating that additional CDC48/p97 substrates await to be identified in the context of mitosis.

Aside DNA metabolism CDC48/p97 executes critical function in the regulation of DNA-dependent RNA synthesis. Of note, failure in accurate regulation of transcription factors controlling metabolism and cell proliferation are associated with oncogenesis (Maneix and Catic, 2016). Chromatin-dependent activity of CDC48/p97 in the regulation of gene expression is especially interesting, as it does not involve subsequent protein degradation (Wilcox and Laney, 2009; Ndoja et al., 2014; Figure 1; Table 1). In yeast, CDC48/p97 controls rapid switch in gene expression through non-proteolytic release of transcription factors from the chromatin. Intriguingly, individual transcription factors that are regulated by CDC48/p97 represent transcriptional activators as well as repressors (Wilcox and Laney, 2009; Ndoja et al., 2014). Thus, CDC48/p97 is capable of initiating fast response toward transcriptional stimuli through attenuation or activation of gene expression. In S. cerevisiae the Ufd1-Npl4 cofactor and Doa10 are linked to transcriptional regulation by CDC48/p97 (Wilcox and Laney, 2009; Ndoja et al., 2014). In mammalian cells CDC48/p97 together with the cofactor UBXN7 and the CUL2-VHL ubiquitin ligase mediates the proteolytic inactivation of HIF1 $\alpha$ transcription factor, suggesting a critical role of CDC48/p97 in the cellular response toward hypoxia (Alexandru et al., 2008). It remains to be shown, whether CDC48/p97mediated regulation of HIF $1 \alpha$ occurs on chromatin. In contrast to the extraction of transcription factors, CDC48/p97 is also implicated in chromatin remodeling. In yeast CDC48 together with Ubx3 (UBXD8) is required for the mono-ubiquitylation on histone $2 \mathrm{~B}$, thus controlling chromatin compaction and presumably differentiation in vertebrates (Bonizec et al., 2014). An alternative pathway controlling gene expression was described in Arabidopsis. Here, CDC48/p97 ${ }^{\mathrm{NPL} 4}$ promotes chromatin de-condensation through regulated disassembly of centromeric heterochromatin, resulting in the release of rRNAs, which facilitates ribosome biogenesis (Merai et al., 2014). Here, SUMOylated centromere components including the centromeric histone variant $\mathrm{CenH} 3$ trigger chromatin relaxation.

\section{CONCLUDING REMARKS}

The described molecular mechanisms illustrate the central role of CDC48/p97 in the dynamic control of protein composition in the chromatin environment (Figure 1; Table 1). CDC48/p97 operates at the intersection of two major signaling pathways at the chromatin, ubiquitylation and SUMOylation. It is currently unclear whether both signaling pathways initiate separate mechanisms (Meerang et al., 2011; Bergink et al., 2013) or whether both pathways eventually converge into a common pathway (Nie et al., 2012; Køhler et al., 2013; Gibbs-Seymour et al., 2015) with CDC48/p97 as nodal point (Figure 1). It is feasible, however, that independent and shared signaling pathways act in parallel. Whereas ubiquitin- and SUMOsignaling are essential in mediating timely response toward genotoxic insults, both modifications need to be removed eventually to restore genome integrity. Regarding ubiquitin signaling, CDC48/p97-dependent processing of substrates on chromatin has exclusively been shown to target either K48linked ubiquitin chains (Ramadan et al., 2007; Meerang et al., 2011; Maric et al., 2014; Moreno et al., 2014) or monoubiquitin (Lin et al., 2015). Whether other linkage-types are involved in $\mathrm{CDC} 48 / \mathrm{p} 97$ regulation at the chromatin remains to be deciphered. Mono-ubiquitin and K63-linked chains are essential in the initial signaling of the molecular response to DSBs (Dantuma and van Attikum, 2016). Thus, the recognition of these modifications by CDC48/p97 may provide additional mechanistic insights in early events at DSBs. In this context, it will be of interest to address which cofactors are involved in either linkage-specific recognition or editing of linkage-types (Figure 1). Due to its diverse functions, global CDC48/p97 inhibition causes pleiotropic defects on chromosome biology. Thus it will be crucial to identify the cofactors that direct specificity and discriminate between distinct pathways. Although CDC48/p97 inhibitors are tested in clinical trial studies with promising properties (Anderson et al., 2015), a more specific targeting might be applicable through the selective manipulation of cofactors. The identification of substrate proteins targeted by CDC48/p97 will allow future studies to uncover the underlying molecular mechanisms in more detail, pointing out commons and differences.

\section{AUTHOR CONTRIBUTIONS}

AF and TH elaborated the concept of the manuscript. AF, LA, and $\mathrm{TH}$ wrote the manuscript. All authors discussed the text and commented on the manuscript.

\section{FUNDING}

$\mathrm{TH}$ is supported by the Deutsche Forschungsgemeinschaft (EXC229, KFO286, HO 2541/8-1, and DIP8 grant 2014376) and the European Research Council (consolidator grant 616499).

\section{ACKNOWLEDGMENTS}

We thank the members of our laboratory for critical discussion and helpful advice on the manuscript. We apologize for not having cited valuable contributions due to size limitation. 


\section{REFERENCES}

Acs, K., Luijsterburg, M. S., Ackermann, L., Salomons, F. A., Hoppe, T., and Dantuma, N. P. (2011). The AAA-ATPase VCP/p97 promotes 53BP1 recruitment by removing L3MBTL1 from DNA double-strand breaks. Nat. Struct. Mol. Biol. 18, 1345-1350. doi: 10.1038/nsmb.2188

Alabert, C., Bukowski-Wills, J. C., Lee, S. B., Kustatscher, G., Nakamura, K., De Lima Alves, F., et al. (2014). Nascent chromatin capture proteomics determines chromatin dynamics during DNA replication and identifies unknown fork components. Nat. Cell Biol. 16, 281-293. doi: 10.1038/ ncb 2918

Alexandru, G., Graumann, J., Smith, G. T., Kolawa, N. J., Fang, R., and Deshaies, R. J. (2008). UBXD7 binds multiple ubiquitin ligases and implicates p97 in HIFlalpha turnover. Cell 134, 804-816. doi: 10.1016/j.cell.2008.06.048

Anderson, D. J., Le Moigne, R., Djakovic, S., Kumar, B., Rice, J., Wong, S., et al. (2015). Targeting the AAA ATPase p97 as an approach to treat cancer through disruption of protein homeostasis. Cancer Cell 28, 653-665. doi: 10.1016/j.ccell.2015.10.002

Anindya, R., Mari, P. O., Kristensen, U., Kool, H., Giglia-Mari, G., Mullenders, L. H., et al. (2010). A ubiquitin-binding domain in Cockayne syndrome B required for transcription-coupled nucleotide excision repair. Mol. Cell 38, 637-648. doi: 10.1016/j.molcel.2010.04.017

Arias, E. E., and Walter, J. C. (2007). Strength in numbers: preventing rereplication via multiple mechanisms in eukaryotic cells. Genes Dev. 21, 497-518. doi: $10.1101 / \operatorname{gad} .1508907$

Baek, G. H., Cheng, H., Kim, I., and Rao, H. (2012). The Cdc48 protein and its cofactor Vms1 are involved in Cdc13 protein degradation. J. Biol. Chem. 287, 26788-26795. doi: 10.1074/jbc.M112.351825

Balakirev, M. Y., Mullally, J. E., Favier, A., Assard, N., Sulpice, E., Lindsey, D. F., et al. (2015). Wss1 metalloprotease partners with Cdc48/Doal in processing genotoxic SUMO conjugates. Elife 8:4. doi: 10.7554/eLife.06763

Balch, W. E., Morimoto, R. I., Dillin, A., and Kelly, J. W. (2008). Adapting proteostasis for disease intervention. Science 319, 916-919. doi: $10.1126 /$ science. 1141448

Ballabeni, A., Melixetian, M., Zamponi, R., Masiero, L., Marinoni, F., and Helin, K. (2004). Human geminin promotes pre-RC formation and DNA replication by stabilizing CDT1 in mitosis. EMBO J. 23, 3122-3132. doi: 10.1038/sj.emboj.7600314

Bandau, S., Knebel, A., Gage, Z. O., Wood, N. T., and Alexandru, G. (2012). UBXN7 docks on neddylated cullin complexes using its UIM motif and causes HIF1 $\alpha$ accumulation. BMC Biol. 10:36. doi: 10.1186/1741-7007-10-36

Banerjee, S., Bartesaghi, A., Merk, A., Rao, P., Bulfer, S. L., Yan, Y., et al. (2016). 2.3 A resolution cryo-EM structure of human p97 and mechanism of allosteric inhibition. Science 351, 871-875. doi: 10.1126/science.aad7974

Barthelme, D., and Sauer, R. T. (2015). Origin and functional evolution of the Cdc48/p97/VCP AAA+ protein unfolding and remodeling machine. J. Mol. Biol. doi: 10.1016/j.jmb.2015.11.015 [Epub ahead of print].

Bekker-Jensen, S., and Mailand, N. (2011). The ubiquitin- and SUMO-dependent signaling response to DNA double-strand breaks. FEBS Lett. 585, 2914-2919. doi: 10.1016/j.febslet.2011.05.056

Bergink, S., Ammon, T., Kern, M., Schermelleh, L., Leonhardt, H., and Jentsch, S. (2013). Role of Cdc48/p97 as a SUMO-targeted segregase curbing Rad51-Rad52 interaction. Nat. Cell Biol. 15, 526-532. doi: 10.1038/ncb2729

Beskow, A., Grimberg, K. B., Bott, L. C., Salomons, F. A., Dantuma, N. P., and Young, P. (2009). A conserved unfoldase activity for the p97 AAAATPase in proteasomal degradation. J. Mol. Biol. 394, 732-746. doi: 10.1016/j.jmb.2009.09.050

Bonizec, M., Herissant, L., Pokrzywa, W., Geng, F., Wenzel, S., Howard, G. C., et al. (2014). The ubiquitin-selective chaperone Cdc48/p97 associates with Ubx3 to modulate monoubiquitylation of histone H2B. Nucleic Acids Res. 42, 10975-10986. doi: 10.1093/nar/gku786

Boskovic, J., Coloma, J., Aparicio, T., Zhou, M., Robinson, C. V., Mendez, J., et al. (2007). Molecular architecture of the human GINS complex. EMBO Rep. 8, 678-684. doi: 10.1038/sj.embor.7401002

Botuyan, M. V., Lee, J., Ward, I. M., Kim, J. E., Thompson, J. R., Chen, J., et al. (2006). Structural basis for the methylation state-specific recognition of histone H4-K20 by 53BP1 and Crb2 in DNA repair. Cell 127, 1361-1373. doi: 10.1016/j.cell.2006.10.043
Brandman, O., Stewart-Ornstein, J., Wong, D., Larson, A., Williams, C. C., Li, G. W., et al. (2012). A ribosome-bound quality control complex triggers degradation of nascent peptides and signals translation stress. Cell 151, 10421054. doi: 10.1016/j.cell.2012.10.044

Braun, S., Matuschewski, K., Rape, M., Thoms, S., and Jentsch, S. (2002). Role of the ubiquitin-selective CDC48(UFD1/NPL4 )chaperone (segregase) in ERAD of OLE1 and other substrates. EMBO J. 21, 615-621. doi: 10.1093/emboj/21.4.615

Brinkmann, K., Schell, M., Hoppe, T., and Kashkar, H. (2015). Regulation of the DNA damage response by ubiquitin conjugation. Front. Genet. 6:98. doi: 10.3389/fgene. 2015.00098

Buchan, J. R., Kolaitis, R. M., Taylor, J. P., and Parker, R. (2013). Eukaryotic stress granules are cleared by autophagy and Cdc48/VCP function. Cell 153, 1461-1474. doi: 10.1016/j.cell.2013.05.037

Buchberger, A., Schindelin, H., and Hanzelmann, P. (2015). Control of p97 function by cofactor binding. FEBS Lett. 589, 2578-2589. doi: 10.1016/j.febslet.2015.08.028

Centore, R. C., Yazinski, S. A., Tse, A., and Zou, L. (2012). Spartan/C1orf124, a reader of PCNA ubiquitylation and a regulator of UV-induced DNA damage response. Mol. Cell 46, 625-635. doi: 10.1016/j.molcel.2012.05.020

Chapman, E., Maksim, N., De La Cruz, F., and La Clair, J. J. (2015). Inhibitors of the AAA + chaperone p97. Molecules 20, 3027-3049. doi: 10.3390/molecules20023027

Chen, S., De Vries, M. A., and Bell, S. P. (2007). Orc6 is required for dynamic recruitment of Cdt1 during repeated Mcm2-7 loading. Genes Dev. 21, 28972907. doi: 10.1101/gad.1596807

Chien, C. Y., and Chen, R. H. (2013). Cdc48 chaperone and adaptor Ubx4 distribute the proteasome in the nucleus for anaphase proteolysis. J. Biol. Chem. 288, 37180-37191. doi: 10.1074/jbc.M113.513598

Ciccia, A., and Elledge, S. J. (2010). The DNA damage response: making it safe to play with knives. Mol. Cell 40, 179-204. doi: 10.1016/j.molcel.2010.09.019

Coleman, K. E., Grant, G. D., Haggerty, R. A., Brantley, K., Shibata, E., Workman, B. D., et al. (2015). Sequential replication-coupled destruction at G1/S ensures genome stability. Genes Dev. 29, 1734-1746. doi: 10.1101/gad.263731.115

Cremona, C. A., Sarangi, P., Yang, Y., Hang, L. E., Rahman, S., and Zhao, X. (2012). Extensive DNA damage-induced sumoylation contributes to replication and repair and acts in addition to the mecl checkpoint. Mol. Cell 45, 422-432. doi: 10.1016/j.molcel.2011.11.028

Cutter, A. R., and Hayes, J. J. (2015). A brief review of nucleosome structure. FEBS Lett. 589, 2914-2922. doi: 10.1016/j.febslet.2015.05.016

Dai, R. M., and Li, C. C. (2001). Valosin-containing protein is a multi-ubiquitin chain-targeting factor required in ubiquitin-proteasome degradation. Nat. Cell Biol. 3, 740-744. doi: 10.1038/35087056

Dammer, E. B., Na, C. H., Xu, P., Seyfried, N. T., Duong, D. M., Cheng, D., et al. (2011). Polyubiquitin linkage profiles in three models of proteolytic stress suggest the etiology of Alzheimer disease. J. Biol. Chem. 286, 10457-10465. doi: 10.1074/jbc.M110.149633

Dantuma, N. P., Acs, K., and Luijsterburg, M. S. (2014). Should I stay or should I go: VCP/p97-mediated chromatin extraction in the DNA damage response. Exp. Cell Res. 329, 9-17. doi: 10.1016/j.yexcr.2014.08.025

Dantuma, N. P., and van Attikum, H. (2016). Spatiotemporal regulation of posttranslational modifications in the DNA damage response. EMBO J. 35, 6-23. doi: 10.15252/embj.201592595

Davidson, I. F., Li, A., and Blow, J. J. (2006). Deregulated replication licensing causes DNA fragmentation consistent with head-to-tail fork collision. Mol. Cell. 24, 433-443. doi: 10.1016/j.molcel.2006.09.010

Davis, A. J., Chen, B. P., and Chen, D. J. (2014). DNA-PK: a dynamic enzyme in a versatile DSB repair pathway. DNA Rep. (Amst) 17, 21-29. doi: 10.1016/j.dnarep.2014.02.020

Davis, E. J., Lachaud, C., Appleton, P., Macartney, T. J., Nathke, I., and Rouse, J. (2012). DVC1 (C1orf124) recruits the p97 protein segregase to sites of DNA damage. Nat. Struct. Mol. Biol. 19, 1093-1100. doi: 10.1038/nsmb.2394

Decottignies, A., Evain, A., and Ghislain, M. (2004). Binding of Cdc48p to a ubiquitin-related UBX domain from novel yeast proteins involved in intracellular proteolysis and sporulation. Yeast 21, 127-139. doi: 10.1002/yea.1071

den Besten, W., Verma, R., Kleiger, G., Oania, R. S., and Deshaies, R. J. (2012). NEDD8 links cullin-RING ubiquitin ligase function to the p97 pathway. Nat. Struct. Mol. Biol. 19, S511. doi: 10.1038/nsmb.2269 
Deshaies, R. J. (2014). Proteotoxic crisis, the ubiquitin-proteasome system, and cancer therapy. BMC Biol. 12:94. doi: 10.1186/s12915-014-0094-0

Dewar, J. M., Budzowska, M., and Walter, J. C. (2015). The mechanism of DNA replication termination in vertebrates. Nature 525, 345-350. doi: 10.1038 /nature 14887

Dobrynin, G., Popp, O., Romer, T., Bremer, S., Schmitz, M. H., Gerlich, D. W., et al. (2011). Cdc48/p97-Ufd1-Npl4 antagonizes Aurora B during chromosome segregation in HeLa cells. J. Cell Sci. 124, 1571-1580. doi: 10.1242/jcs. 069500

Dungrawala, H., Rose, K. L., Bhat, K. P., Mohni, K. N., Glick, G. G., Couch, F. B., et al. (2015). The Replication checkpoint prevents two types of fork collapse without regulating replisome stability. Mol. Cell 59, 998-1010. doi: 10.1016/j.molcel.2015.07.030

Duxin, J. P., Dewar, J. M., Yardimci, H., and Walter, J. C. (2014). Repair of a DNA-protein crosslink by replication-coupled proteolysis. Cell 159, 346-357. doi: $10.1016 /$ j.cell.2014.09.024

Duxin, J. P., and Walter, J. C. (2015). What is the DNA repair defect underlying Fanconi anemia? Curr. Opin. Cell. Biol. 37, 49-60. doi: 10.1016/j.ceb.2015.09.002

Duzdevich, D., Warner, M. D., Ticau, S., Ivica, N. A., Bell, S. P., and Greene, E. C. (2015). The dynamics of eukaryotic replication initiation: origin specificity, licensing, and firing at the single-molecule level. Mol. Cell 58, 483-494. doi: 10.1016/j.molcel.2015.03.017

Epshtein, V., Kamarthapu, V., Mcgary, K., Svetlov, V., Ueberheide, B., Proshkin, S., et al. (2014). UvrD facilitates DNA repair by pulling RNA polymerase backwards. Nature 505, 372-377. doi: 10.1038/nature12928

Fang, L., Hemion, C., Bento, A. C., Bippes, C. C., Flammer, J., and Neutzner, A. (2015). Mitochondrial function in neuronal cells depends on p97/VCP/Cdc48-mediated quality control. Front. Cell. Neurosci. 9:16. doi: $10.3389 /$ fncel.2015.00016

Feng, H., and Kipreos, E. T. (2003). Preventing DNA re-replication-divergent safeguards in yeast and metazoa. Cell Cycle 2, 431-434. doi: 10.4161/cc.2.5.527

Fessart, D., Marza, E., Taouji, S., Delom, F., and Chevet, E. (2013). P97/CDC48: proteostasis control in tumor cell biology. Cancer Lett. 337, 26-34. doi: 10.1016/j.canlet.2013.05.030

Forget, A. L., and Kowalczykowski, S. C. (2012). Single-molecule imaging of DNA pairing by RecA reveals a three-dimensional homology search. Nature 482, 423-427. doi: 10.1038/nature10782

Fousteri, M., Vermeulen, W., Van Zeeland, A. A., and Mullenders, L. H. (2006). Cockayne syndrome A and B proteins differentially regulate recruitment of chromatin remodeling and repair factors to stalled RNA polymerase II in vivo. Mol. Cell 23, 471-482. doi: 10.1016/j.molcel.2006.06.029

Fragkos, M., Ganier, O., Coulombe, P., and Mechali, M. (2015). DNA replication origin activation in space and time. Nat. Rev. Mol. Cell Biol. 16, 360-374. doi: $10.1038 / \mathrm{nrm} 4002$

Franz, A., Ackermann, L., and Hoppe, T. (2014). Create and preserve: proteostasis in development and aging is governed by Cdc48/p97/VCP. Biochim. Biophys. Acta 1843, 205-215. doi: 10.1016/j.bbamcr.2013.03.031

Franz, A., Orth, M., Pirson, P. A., Sonneville, R., Blow, J. J., Gartner, A., et al. (2011). CDC-48/p97 coordinates CDT-1 degradation with GINS chromatin dissociation to ensure faithful DNA replication. Mol. Cell 44, 85-96. doi: 10.1016/j.molcel.2011.08.028

Franz, A., Pirson, P. A., Pilger, D., Halder, S., Achuthankutty, D., Kashkar, H., et al. (2016). Chromatin-associated degradation is defined by UBXN-3/FAF1 to safeguard DNA replication fork progression. Nat. Commun. 7:10612. doi: $10.1038 /$ ncomms 10612

Frigola, J., Remus, D., Mehanna, A., and Diffley, J. F. (2013). ATPase-dependent quality control of DNA replication origin licensing. Nature 495, 339-343. doi: $10.1038 /$ nature 11920

Gambus, A., Jones, R. C., Sanchez-Diaz, A., Kanemaki, M., Van Deursen, F., Edmondson, R. D., et al. (2006). GINS maintains association of Cdc45 with MCM in replisome progression complexes at eukaryotic DNA replication forks. Nat. Cell Biol. 8, 358-366. doi: 10.1038/ncb1382

Ghislain, M., Dohmen, R. J., Levy, F., and Varshavsky, A. (1996). Cdc48p interacts with Ufd3p, a WD repeat protein required for ubiquitin-mediated proteolysis in Saccharomyces cerevisiae. EMBO J. 15, 4884-4899.

Ghosal, G., Leung, J. W., Nair, B. C., Fong, K. W., and Chen, J. (2012). Proliferating cell nuclear antigen (PCNA)-binding protein C1orf124 is a regulator of translesion synthesis. J. Biol. Chem. 287, 34225-34233. doi: 10.1074/jbc.M112.400135

Gibbs-Seymour, I., Oka, Y., Rajendra, E., Weinert, B. T., Passmore, L. A., Patel, K. J., et al. (2015). Ubiquitin-SUMO circuitry controls activated fanconi anemia ID complex dosage in response to DNA damage. Mol. Cell 57, 150-164. doi: 10.1016/j.molcel.2014.12.001

Godderz, D., Heinen, C., Marchese, F. P., Kurz, T., Acs, K., and Dantuma, N. P. (2015). Cdc48-independent proteasomal degradation coincides with a reduced need for ubiquitylation. Sci. Rep. 5:7615. doi: 10.1038/srep07615

Hardeland, U., Steinacher, R., Jiricny, J., and Schar, P. (2002). Modification of the human thymine-DNA glycosylase by ubiquitin-like proteins facilitates enzymatic turnover. EMBO J. 21, 1456-1464. doi: 10.1093/emboj/21. 6.1456

Hartmann-Petersen, R., Wallace, M., Hofmann, K., Koch, G., Johnsen, A. H., Hendil, K. B., et al. (2004). The Ubx2 and Ubx3 cofactors direct Cdc48 activity to proteolytic and nonproteolytic ubiquitin-dependent processes. Curr. Biol. 14, 824-828. doi: 10.1016/j.cub.2004.04.029

Havens, C. G., and Walter, J. C. (2009). Docking of a specialized PIP Box onto chromatin-bound PCNA creates a degron for the ubiquitin ligase CRL4Cdt2. Mol. Cell 35, 93-104. doi: 10.1016/j.molcel.2009.05.012

Haynes, B., Saadat, N., Myung, B., and Shekhar, M. P. (2015). Crosstalk between translesion synthesis, Fanconi anemia network, and homologous recombination repair pathways in interstrand DNA crosslink repair and development of chemoresistance. Mutat. Res. Rev. Mutat. Res. 763, 258-266. doi: 10.1016/j.mrrev.2014.11.005

He, J., Zhu, Q., Wani, G., Sharma, N., Han, C., Qian, J., et al. (2014). Ubiquitin-specific protease 7 regulates nucleotide excision repair through deubiquitinating XPC protein and preventing XPC protein from undergoing ultraviolet light-induced and VCP/p97 protein-regulated proteolysis. J. Biol. Chem. 289, 27278-27289. doi: 10.1074/jbc.M114.589812

He, J., Zhu, Q., Wani, G., Sharma, N., and Wani, A. A. (2016). VCP/p97 segregase mediates proteolytic processing of CSB in damaged chromatin. J. Biol. Chem. 291, 7396-7408. doi: 10.1074/jbc.M115.705350

Hemion, C., Flammer, J., and Neutzner, A. (2014). Quality control of oxidatively damaged mitochondrial proteins is mediated by p97 and the proteasome. Free Radic. Biol. Med. 75, 121-128. doi: 10.1016/j.freeradbiomed.2014. 07.016

Heo, J. M., Livnat-Levanon, N., Taylor, E. B., Jones, K. T., Dephoure, N., Ring, J., et al. (2010). A stress-responsive system for mitochondrial protein degradation. Mol. Cell 40, 465-480. doi: 10.1016/j.molcel.2010.10.021

Heride, C., Urbe, S., and Clague, M. J. (2014). Ubiquitin code assembly and disassembly. Curr. Biol. 24, R215-R220. doi: 10.1016/j.cub.2014.02.002

Hoeijmakers, J. H. (2001). Genome maintenance mechanisms for preventing cancer. Nature 411, 366-374. doi: 10.1038/35077232

Hoeijmakers, J. H. (2009). DNA damage, aging, and cancer. N. Engl. J. Med. 361, 1475-1485. doi: 10.1056/NEJMra0804615

Holthausen, J. T., Wyman, C., and Kanaar, R. (2010). Regulation of DNA strand exchange in homologous recombination. DNA Repair (Amst) 9, 1264-1272. doi: 10.1016/j.dnarep.2010.09.014

Hoogstraten, D., Bergink, S., Ng, J. M., Verbiest, V. H., Luijsterburg, M. S., Geverts, B., et al. (2008). Versatile DNA damage detection by the global genome nucleotide excision repair protein XPC. J. Cell Sci. 121, 2850-2859. doi: $10.1242 /$ jcs.031708

Hoppe, T. (2005). Multiubiquitylation by E4 enzymes: 'one size' doesn't fit all. Trends Biochem. Sci. 30, 183-187. doi: 10.1016/j.tibs.2005.02.004

Hu, J., Mccall, C. M., Ohta, T., and Xiong, Y. (2004). Targeted ubiquitination of CDT1 by the DDB1-CUL4A-ROC1 ligase in response to DNA damage. Nat. Cell Biol. 6, 1003-1009. doi: 10.1038/ncb1172

Ilves, I., Petojevic, T., Pesavento, J. J., and Botchan, M. R. (2010). Activation of the MCM2-7 helicase by association with Cdc45 and GINS proteins. Mol. Cell 37, 247-258. doi: 10.1016/j.molcel.2009.12.030

Jackson, S. P., and Bartek, J. (2009). The DNA-damage response in human biology and disease. Nature 461, 1071-1078. doi: 10.1038/nature08467

Jackson, S. P., and Durocher, D. (2013). Regulation of DNA damage responses by ubiquitin and SUMO. Mol. Cell 49, 795-807. doi: 10.1016/j.molcel.2013.01.017

Jagannathan, M., Nguyen, T., Gallo, D., Luthra, N., Brown, G. W., Saridakis, V., et al. (2014). A role for USP7 in DNA replication. Mol. Cell. Biol. 34, 132-145. doi: $10.1128 /$ MCB.00639-13 
Jarosch, E., Taxis, C., Volkwein, C., Bordallo, J., Finley, D., Wolf, D. H., et al. (2002). Protein dislocation from the ER requires polyubiquitination and the AAA-ATPase Cdc48. Nat. Cell Biol. 4, 134-139. doi: 10.1038/ncb746

Jentsch, S., and Rumpf, S. (2007). Cdc48 (p97): a "molecular gearbox" in the ubiquitin pathway? Trends Biochem. Sci. 32, 6-11. doi: 10.1016/j.tibs.2006.11.005

Jiang, N., Shen, Y., Fei, X., Sheng, K., Sun, P., Qiu, Y., et al. (2013). Valosincontaining protein regulates the proteasome-mediated degradation of DNAPKcs in glioma cells. Cell Death Dis 4, e647. doi: 10.1038/cddis.2013.171

Jin, J., Arias, E. E., Chen, J., Harper, J. W., and Walter, J. C. (2006). A family of diverse Cul4-Ddb1-interacting proteins includes Cdt2, which is required for $S$ phase destruction of the replication factor Cdt1. Mol. Cell 23, 709-721. doi: 10.1016/j.molcel.2006.08.010

Johnson, J. O., Mandrioli, J., Benatar, M., Abramzon, Y., Van Deerlin, V. M., Trojanowski, J. Q., et al. (2010). Exome sequencing reveals VCP mutations as a cause of familial ALS. Neuron 68, 857-864. doi: 10.1016/j.neuron.2010.11.036

Ju, J. S., Fuentealba, R. A., Miller, S. E., Jackson, E., Piwnica-Worms, D., Baloh, R. H., et al. (2009). Valosin-containing protein (VCP) is required for autophagy and is disrupted in VCP disease. J. Cell Biol. 187, 875-888. doi: 10.1083/jcb.200908115

Juhasz, S., Balogh, D., Hajdu, I., Burkovics, P., Villamil, M. A., Zhuang, Z., et al. (2012). Characterization of human Spartan/C1orf124, an ubiquitin-PCNA interacting regulator of DNA damage tolerance. Nucleic Acids Res. 40, 1079510808. doi: $10.1093 /$ nar/gks850

Kim, M. S., Machida, Y., Vashisht, A. A., Wohlschlegel, J. A., Pang, Y. P., and Machida, Y. J. (2013). Regulation of error-prone translesion synthesis by Spartan/C1orf124. Nucleic Acids Res. 41, 1661-1668. doi: 10.1093/nar/gks1267

Kim, Y., and Kipreos, E. T. (2007). Cdt1 degradation to prevent DNA rereplication: conserved and non-conserved pathways. Cell Div 2, 18. doi: 10.1186/1747-1028-2-18

Klein, H. L. (2008). The consequences of Rad51 overexpression for normal and tumor cells. DNA Rep. (Amst.) 7, 686-693. doi: 10.1016/j.dnarep.2007.12.008

Kloppsteck, P., Ewens, C. A., Forster, A., Zhang, X., and Freemont, P. S. (2012). Regulation of $\mathrm{p} 97$ in the ubiquitin-proteasome system by the UBX protein-family. Biochim. Biophys. Acta 1823, 125-129. doi: 10.1016/j.bbamcr.2011.09.006

Koegl, M., Hoppe, T., Schlenker, S., Ulrich, H. D., Mayer, T. U., and Jentsch, S. (1999). A novel ubiquitination factor, E4, is involved in multiubiquitin chain assembly. Cell 96, 635-644. doi: 10.1016/S0092-8674(00)80574-7

Køhler, J. B., Jørgensen, M. L., Beinoraite, G., Thorsen, M., and Thon, G. (2013). Concerted action of the ubiquitin-fusion degradation protein 1 (Ufd1) and Sumo-targeted ubiquitin ligases (STUbLs) in the DNA-damage response. PLoS ONE 8:e80442. doi: 10.1371/journal.pone.0080442

Køhler, J. B., Tammsalu, T., Jørgensen, M. M., Steen, N., Hay, R. T., and Thon, G. (2015). Targeting of SUMO substrates to a Cdc48-Ufd1-Npl4 segregase and STUbL pathway in fission yeast. Nat. Commun. 6:8827. doi: $10.1038 /$ ncomms 9827

Kowalczykowski, S. C. (2015). An Overview of the Molecular Mechanisms of Recombinational DNA Repair. Cold Spring Harb. Perspect. Biol. 7, 1-37. doi: 10.1101/cshperspect.a016410

Krick, R., Bremer, S., Welter, E., Schlotterhose, P., Muehe, Y., Eskelinen, E. L., et al. (2010). Cdc48/p97 and Shp1/p47 regulate autophagosome biogenesis in concert with ubiquitin-like Atg8. J. Cell Biol. 190, 965-973. doi: 10.1083/jcb.201002075

Kubota, Y., Takase, Y., Komori, Y., Hashimoto, Y., Arata, T., Kamimura, Y., et al. (2003). A novel ring-like complex of Xenopus proteins essential for the initiation of DNA replication. Genes Dev. 17, 1141-1152. doi: 10.1101/gad.1070003

Kuhlbrodt, K., Janiesch, P. C., Kevei, E., Segref, A., Barikbin, R., and Hoppe, T. (2011). The Machado-Joseph disease deubiquitylase ATX-3 couples longevity and proteostasis. Nat. Cell Biol. 13, 273-281. doi: 10.1038/ncb2200

Lessel, D., Vaz, B., Halder, S., Lockhart, P. J., Marinovic-Terzic, I., LopezMosqueda, J., et al. (2014). Mutations in SPRTN cause early onset hepatocellular carcinoma, genomic instability and progeroid features. Nat. Genet. 46, 1239-1244. doi: 10.1038/ng.3103

Lieber, M. R. (2010). The mechanism of double-strand DNA break repair by the nonhomologous DNA end-joining pathway. Annu. Rev. Biochem. 79, 181-211. doi: 10.1146/annurev.biochem.052308.093131

Lin, K. W., Mcdonald, K. R., Guise, A. J., Chan, A., Cristea, I. M., and Zakian, V. A. (2015). Proteomics of yeast telomerase identified Cdc48-Npl4-Ufd1 and
Ufd4 as regulators of Est1 and telomere length. Nat. Commun. 6:8290. doi: $10.1038 /$ ncomms 9290

Livingstone, M., Ruan, H., Weiner, J., Clauser, K. R., Strack, P., Jin, S., et al. (2005). Valosin-containing protein phosphorylation at Ser784 in response to DNA damage. Cancer Res. 65, 7533-7540.

Long, D. T., Joukov, V., Budzowska, M., and Walter, J. C. (2014). BRCA1 promotes unloading of the CMG helicase from a stalled DNA replication fork. Mol. Cell. 56, 174-185. doi: 10.1016/j.molcel.2014.08.012

Lydeard, J. R., Lipkin-Moore, Z., Sheu, Y. J., Stillman, B., Burgers, P. M., and Haber, J. E. (2010). Break-induced replication requires all essential DNA replication factors except those specific for pre-RC assembly. Genes Dev. 24, 1133-1144. doi: $10.1101 / \operatorname{gad} .1922610$

Maculins, T., Nkosi, P. J., Nishikawa, H., and Labib, K. (2015). Tethering of SCF(Dia2) to the replisome promotes efficient ubiquitylation and disassembly of the CMG helicase. Curr. Biol. 25, 2254-2259. doi: 10.1016/j.cub.2015.07.012

Maneix, L., and Catic, A. (2016). Touch and Go -Nuclear proteolysis in the regulation of metabolic genes and cancer. FEBS Lett. 20, 5546-5553. doi: 10.1002/1873-3468.12087

Maric, M., Maculins, T., De Piccoli, G., and Labib, K. (2014). Cdc48 and a ubiquitin ligase drive disassembly of the CMG helicase at the end of DNA replication. Science 346, 1253596. doi: 10.1126/science. 1253596

Marteijn, J. A., Lans, H., Vermeulen, W., and Hoeijmakers, J. H. (2014). Understanding nucleotide excision repair and its roles in cancer and ageing. Nat. Rev. Mol. Cell Biol. 15, 465-481. doi: 10.1038/nrm3822

Masai, H., Matsumoto, S., You, Z., Yoshizawa-Sugata, N., and Oda, M. (2010). Eukaryotic chromosome DNA replication: where, when, and how? Annu. Rev. Biochem. 79, 89-130. doi: 10.1146/annurev.biochem.052308.103205

Maskey, R. S., Kim, M. S., Baker, D. J., Childs, B., Malureanu, L. A., Jeganathan, K. B., et al. (2014). Spartan deficiency causes genomic instability and progeroid phenotypes. Nat. Commun. 5:5744. doi: 10.1038/ncomms6744

Medicherla, B., Kostova, Z., Schaefer, A., and Wolf, D. H. (2004). A genomic screen identifies Dsk2p and Rad23p as essential components of ER-associated degradation. EMBO Rep. 5, 692-697. doi: 10.1038/sj.embor.7400164

Meerang, M., Ritz, D., Paliwal, S., Garajova, Z., Bosshard, M., Mailand, N., et al. (2011). The ubiquitin-selective segregase $\mathrm{VCP} / \mathrm{p} 97$ orchestrates the response to DNA double-strand breaks. Nat. Cell Biol. 13, 1376-1382. doi: 10.1038/ ncb2367

Mehta, A., and Haber, J. E. (2014). Sources of DNA double-strand breaks and models of recombinational DNA repair. Cold Spring Harb. Perspect. Biol. 6:a016428. doi: 10.1101/cshperspect.a016428

Merai, Z., Chumak, N., Garcia-Aguilar, M., Hsieh, T. F., Nishimura, T., Schoft, V. K., et al. (2014). The AAA-ATPase molecular chaperone Cdc48/p97 disassembles sumoylated centromeres, decondenses heterochromatin, and activates ribosomal RNA genes. Proc. Natl. Acad. Sci. U.S.A. 111, 16166-16171. doi: $10.1073 /$ pnas. 1418564111

Meyer, H., and Weihl, C. C. (2014). The VCP/p97 system at a glance: connecting cellular function to disease pathogenesis. J. Cell Sci. 127, 3877-3883. doi: $10.1242 /$ jcs.093831

Meyer, H. H., Shorter, J. G., Seemann, J., Pappin, D., and Warren, G. (2000). A complex of mammalian ufd 1 and npl4 links the AAA-ATPase, p97, to ubiquitin and nuclear transport pathways. EMBO J. 19, 2181-2192. doi: 10.1093/emboj/19.10.2181

Min, J., Allali-Hassani, A., Nady, N., Qi, C., Ouyang, H., Liu, Y., et al. (2007). L3MBTL1 recognition of mono- and dimethylated histones. Nat. Struct. Mol. Biol. 14, 1229-1230. doi: 10.1038/nsmb1340

Misteli, T. (2007). Beyond the sequence: cellular organization of genome function. Cell 128, 787-800. doi: 10.1016/j.cell.2007.01.028

Moreno, S. P., Bailey, R., Campion, N., Herron, S., and Gambus, A. (2014). Polyubiquitylation drives replisome disassembly at the termination of DNA replication. Science 346, 477-481. doi: 10.1126/science.1253585

Mosbech, A., Gibbs-Seymour, I., Kagias, K., Thorslund, T., Beli, P., Povlsen, L., et al. (2012). DVC1 (C1orf124) is a DNA damage-targeting p97 adaptor that promotes ubiquitin-dependent responses to replication blocks. Nat. Struct. Mol. Biol. 19, 1084-1092. doi: 10.1038/nsmb.2395

Mouysset, J., Deichsel, A., Moser, S., Hoege, C., Hyman, A. A., Gartner, A., et al. (2008). Cell cycle progression requires the CDC-48UFD-1/NPL-4 complex for efficient DNA replication. Proc. Natl. Acad. Sci. U.S.A. 105, 12879-12884. doi: 10.1073/pnas.0805944105 
Moyer, S. E., Lewis, P. W., and Botchan, M. R. (2006). Isolation of the Cdc45/Mcm2-7/GINS (CMG) complex, a candidate for the eukaryotic DNA replication fork helicase. Proc. Natl. Acad. Sci. U.S.A. 103, 10236-10241. doi: 10.1073/pnas.0602400103

Mullen, J. R., Chen, C. F., and Brill, S. J. (2010). Wss1 is a SUMO-dependent isopeptidase that interacts genetically with the Slx5-Slx8 SUMO-targeted ubiquitin ligase. Mol. Cell. Biol. 30, 3737-3748. doi: 10.1128/MCB.01649-09

Mullenders, L. (2015). DNA damage mediated transcription arrest: step back to go forward. DNA Repair (Amst) 36, 28-35. doi: 10.1016/j.dnarep.2015. 09.005

Nalbandian, A., Donkervoort, S., Dec, E., Badadani, M., Katheria, V., Rana, P., et al. (2011). The multiple faces of valosin-containing protein-associated diseases: inclusion body myopathy with Paget's disease of bone, frontotemporal dementia, and amyotrophic lateral sclerosis. J. Mol. Neurosci. 45, 522-531. doi: 10.1007/s12031-011-9627-y

Ndoja, A., Cohen, R. E., and Yao, T. (2014). Ubiquitin signals proteolysisindependent stripping of transcription factors. Mol. Cell 53, 893-903. doi: 10.1016/j.molcel.2014.02.002

Neuber, O., Jarosch, E., Volkwein, C., Walter, J., and Sommer, T. (2005). Ubx2 links the Cdc48 complex to ER-associated protein degradation. Nat. Cell Biol. 7, 993-998. doi: 10.1038/ncb1298

Nie, M., Aslanian, A., Prudden, J., Heideker, J., Vashisht, A. A., Wohlschlegel, J. A., et al. (2012). Dual recruitment of Cdc48 (p97)-Ufd1-Npl4 ubiquitin-selective segregase by small ubiquitin-like modifier protein (SUMO) and ubiquitin in SUMO-targeted ubiquitin ligase-mediated genome stability functions. J. Biol. Chem. 287, 29610-29619. doi: 10.1074/jbc.M112.379768

Olzmann, J. A., Richter, C. M., and Kopito, R. R. (2013). Spatial regulation of UBXD8 and p97/VCP controls ATGL-mediated lipid droplet turnover. Proc. Natl. Acad. Sci. U.S.A. 110, 1345-1350. doi: 10.1073/pnas.1213 738110

Ossareh-Nazari, B., Bonizec, M., Cohen, M., Dokudovskaya, S., Delalande, F., Schaeffer, C., et al. (2010). Cdc48 and Ufd3, new partners of the ubiquitin protease Ubp3, are required for ribophagy. EMBO Rep. 11, 548-554. doi: 10.1038/embor.2010.74

Park, S., Isaacson, R., Kim, H. T., Silver, P. A., and Wagner, G. (2005). Ufd1 exhibits the AAA-ATPase fold with two distinct ubiquitin interaction sites. Structure 13, 995-1005. doi: 10.1016/j.str.2005.04.013

Partridge, J. J., Lopreiato, J. O. Jr., Latterich, M., and Indig, F. E. (2003). DNA damage modulates nucleolar interaction of the Werner protein with the AAA ATPase p97/VCP. Mol. Biol. Cell 14, 4221-4229. doi: 10.1091/mbc.E03-02-0111

Polo, S. E., and Jackson, S. P. (2011). Dynamics of DNA damage response proteins at DNA breaks: a focus on protein modifications. Genes Dev. 25, 409-433. doi: 10.1101/gad.2021311

Psakhye, I., and Jentsch, S. (2012). Protein group modification and synergy in the SUMO pathway as exemplified in DNA repair. Cell 151, 807-820. doi: 10.1016/j.cell.2012.10.021

Puumalainen, M. R., Lessel, D., Ruthemann, P., Kaczmarek, N., Bachmann, K., Ramadan, K., et al. (2014). Chromatin retention of DNA damage sensors DDB2 and XPC through loss of p97 segregase causes genotoxicity. Nat. Commun. 5:3695. doi: 10.1038 /ncomms4695

Rabinovich, E., Kerem, A., Frohlich, K. U., Diamant, N., and Bar-Nun, S. (2002). AAA-ATPase p97/Cdc48p, a cytosolic chaperone required for endoplasmic reticulum-associated protein degradation. Mol. Cell. Biol. 22, 626-634. doi: 10.1128/MCB.22.2.626-634.2002

Ramadan, K., Bruderer, R., Spiga, F. M., Popp, O., Baur, T., Gotta, M., et al. (2007). Cdc48/p97 promotes reformation of the nucleus by extracting the kinase Aurora B from chromatin. Nature 450, 1258-1262. doi: 10.1038/nature06388

Raman, M., Havens, C. G., Walter, J. C., and Harper, J. W. (2011). A genome-wide screen identifies p97 as an essential regulator of DNA damage-dependent CDT1 destruction. Mol. Cell 44, 72-84. doi: 10.1016/j.molcel.2011.06.036

Raman, M., Sergeev, M., Garnaas, M., Lydeard, J. R., Huttlin, E. L., Goessling, W., et al. (2015). Systematic proteomics of the VCP-UBXD adaptor network identifies a role for UBXN10 in regulating ciliogenesis. Nat. Cell Biol. 17, 1356-1369. doi: 10.1038/ncb3238

Rape, M., Hoppe, T., Gorr, I., Kalocay, M., Richly, H., and Jentsch, S. (2001). Mobilization of processed, membrane-tethered SPT23 transcription factor by CDC48(UFD1/NPL4), a ubiquitin-selective chaperone. Cell 107, 667-677. doi: 10.1016/S0092-8674(01)00595-5
Raschle, M., Smeenk, G., Hansen, R. K., Temu, T., Oka, Y., Hein, M. Y., et al. (2015). DNA repair. Proteomics reveals dynamic assembly of repair complexes during bypass of DNA cross-links. Science 348, 1253671. doi: 10.1126/science.12 53671

Ren, J., Pashkova, N., Winistorfer, S., and Piper, R. C. (2008). DOA1/UFD3 plays a role in sorting ubiquitinated membrane proteins into multivesicular bodies. J. Biol. Chem. 283, 21599-21611. doi: 10.1074/jbc.M802982200

Richardson, C., Stark, J. M., Ommundsen, M., and Jasin, M. (2004). Rad51 overexpression promotes alternative double-strand break repair pathways and genome instability. Oncogene 23, 546-553. doi: 10.1038/sj.onc.1207098

Richly, H., Rape, M., Braun, S., Rumpf, S., Hoege, C., and Jentsch, S. (2005). A series of ubiquitin binding factors connects CDC48/p97 to substrate multiubiquitylation and proteasomal targeting. Cell 120, 73-84. doi: 10.1016/j.cell.2004.11.013

Ritz, D., Vuk, M., Kirchner, P., Bug, M., Schutz, S., Hayer, A., et al. (2011). Endolysosomal sorting of ubiquitylated caveolin-1 is regulated by VCP and UBXD1 and impaired by VCP disease mutations. Nat. Cell Biol. 13, 1116-1123. doi: $10.1038 /$ ncb2301

Rouiller, I., Delabarre, B., May, A. P., Weis, W. I., Brunger, A. T., Milligan, R. A., et al. (2002). Conformational changes of the multifunction p97 AAA ATPase during its ATPase cycle. Nat. Struct. Biol. 9, 950-957. doi: 10.1038/nsb872

Rumpf, S., and Jentsch, S. (2006). Functional division of substrate processing cofactors of the ubiquitin-selective Cdc48 chaperone. Mol. Cell. 21, 261-269. doi: 10.1016/j.molcel.2005.12.014

San Filippo, J., Sung, P., and Klein, H. (2008). Mechanism of eukaryotic homologous recombination. Аnnu. Rev. Biochem. 77, 229-257. doi: 10.1146/annurev.biochem.77.061306.125255

Sasagawa, Y., Higashitani, A., Urano, T., Ogura, T., and Yamanaka, K. (2012). CDC-48/p97 is required for proper meiotic chromosome segregation via controlling AIR-2/Aurora B kinase localization in Caenorhabditis elegans. J. Struct. Biol. 179, 104-111. doi: 10.1016/j.jsb.2012.06.009

Schuberth, C., and Buchberger, A. (2005). Membrane-bound Ubx2 recruits Cdc48 to ubiquitin ligases and their substrates to ensure efficient ER-associated protein degradation. Nat. Cell Biol. 7, 999-1006. doi: 10.1038/ncb1299

Schuberth, C., Richly, H., Rumpf, S., and Buchberger, A. (2004). Shp1 and Ubx2 are adaptors of $\mathrm{Cdc} 48$ involved in ubiquitin-dependent protein degradation. $E M B O$ Rep. 5, 818-824. doi: 10.1038/sj.embor.7400203

Senga, T., Sivaprasad, U., Zhu, W., Park, J. H., Arias, E. E., Walter, J. C., et al. (2006). PCNA is a cofactor for Cdt1 degradation by CUL4/DDB1-mediated N-terminal ubiquitination. J. Biol. Chem. 281, 6246-6252. doi: 10.1074/jbc.M512 705200

Shcherbik, N., and Haines, D. S. (2007). Cdc48p(Npl4p/Ufd1p) binds and segregates membrane-anchored/tethered complexes via a polyubiquitin signal present on the anchors. Mol. Cell 25, 385-397. doi: 10.1016/j.molcel.2007. 01.024

Sirbu, B. M., Mcdonald, W. H., Dungrawala, H., Badu-Nkansah, A., Kavanaugh, G. M., Chen, Y., et al. (2013). Identification of proteins at active, stalled, and collapsed replication forks using isolation of proteins on nascent DNA (iPOND) coupled with mass spectrometry. J. Biol. Chem. 288, 31458-31467. doi: 10.1074/jbc.M113.511337

Song, C., Wang, Q., Song, C., and Rogers, T. J. (2015). Valosin-containing protein $(\mathrm{VCP} / \mathrm{p} 97)$ is capable of unfolding polyubiquitinated proteins through its ATPase domains. Biochem. Biophys. Res. Commun. 463, 453-457. doi: 10.1016/j.bbrc.2015.05.111

Song, E. J., Yim, S. H., Kim, E., Kim, N. S., and Lee, K. J. (2005). Human Fas-associated factor 1, interacting with ubiquitinated proteins and valosincontaining protein, is involved in the ubiquitin-proteasome pathway. Mol. Cell. Biol. 25, 2511-2524. doi: 10.1128/MCB.25.6.2511-2524.2005

Sonoda, E., Sasaki, M. S., Buerstedde, J. M., Bezzubova, O., Shinohara, A., Ogawa, H., et al. (1998). Rad51-deficient vertebrate cells accumulate chromosomal breaks prior to cell death. EMBO J. 17, 598-608. doi: 10.1093/emboj/17.2.598

Sowa, M. E., Bennett, E. J., Gygi, S. P., and Harper, J. W. (2009). Defining the human deubiquitinating enzyme interaction landscape. Cell 138, 389-403. doi: 10.1016/j.cell.2009.04.042

Spivak, G., and Ganesan, A. K. (2014). The complex choreography of transcription-coupled repair. DNA Repair (Amst) 19, 64-70. doi: 10.1016/j.dnarep.2014.03.025 
Stingele, J., Habermann, B., and Jentsch, S. (2015). DNA-protein crosslink repair: proteases as DNA repair enzymes. Trends Biochem. Sci. 40, 67-71. doi: 10.1016/j.tibs.2014.10.012

Stingele, J., and Jentsch, S. (2015). DNA-protein crosslink repair. Nat. Rev. Mol. Cell Biol. 16, 455-460. doi: 10.1038/nrm4015

Stingele, J., Schwarz, M. S., Bloemeke, N., Wolf, P. G., and Jentsch, S. (2014). A DNA-dependent protease involved in DNA-protein crosslink repair. Cell 158, 327-338. doi: 10.1016/j.cell.2014.04.053

Stolz, A., Hilt, W., Buchberger, A., and Wolf, D. H. (2011). Cdc48: a power machine in protein degradation. Trends Biochem. Sci. 36, 515-523. doi: 10.1016/j.tibs.2011.06.001

Sugimoto, N., Yoshida, K., Tatsumi, Y., Yugawa, T., Narisawa-Saito, M., Waga, S., et al. (2009). Redundant and differential regulation of multiple licensing factors ensures prevention of re-replication in normal human cells. J. Cell Sci. 122, 1184-1191. doi: 10.1242/jcs.041889

Tanaka, S., and Diffley, J. F. (2002). Interdependent nuclear accumulation of budding yeast Cdt1 and Mcm2-7 during G1 phase. Nat. Cell Biol. 4, 198-207. doi: $10.1038 /$ ncb757

Tatsumi, Y., Sugimoto, N., Yugawa, T., Narisawa-Saito, M., Kiyono, T., and Fujita, M. (2006). Deregulation of Cdt1 induces chromosomal damage without rereplication and leads to chromosomal instability. J. Cell Sci. 119, 3128-3140. doi: $10.1242 /$ jcs. 03031

Tresse, E., Salomons, F. A., Vesa, J., Bott, L. C., Kimonis, V., Yao, T. P., et al. (2010). $\mathrm{VCP} / \mathrm{p} 97$ is essential for maturation of ubiquitin-containing autophagosomes and this function is impaired by mutations that cause IBMPFD. Autophagy 6, 217-227. doi: 10.4161/auto.6.2.11014

Trusch, F., Matena, A., Vuk, M., Koerver, L., Knaevelsrud, H., Freemont, P. S., et al. (2015). The N-terminal region of the ubiquitin regulatory X (UBX) domaincontaining protein 1 (UBXD1) modulates interdomain communication within the valosin-containing protein p97. J. Biol. Chem. 290, 29414-29427. doi: 10.1074/jbc.M115.680686

Tsuzuki, T., Fujii, Y., Sakumi, K., Tominaga, Y., Nakao, K., Sekiguchi, M., et al. (1996). Targeted disruption of the Rad51 gene leads to lethality in embryonic mice. Proc. Natl. Acad. Sci. U.S.A. 93, 6236-6240. doi: 10.1073/pnas.93.13.6236

Vaz, B., Halder, S., and Ramadan, K. (2013). Role of p97/VCP (Cdc48) in genome stability. Front. Genet. 4:60. doi: 10.3389/fgene.2013.00060

Verma, R., Oania, R., Fang, R., Smith, G. T., and Deshaies, R. J. (2011). Cdc48/p97 mediates UV-dependent turnover of RNA Pol II. Mol. Cell 41, 82-92. doi: 10.1016/j.molcel.2010.12.017

Verma, R., Oania, R. S., Kolawa, N. J., and Deshaies, R. J. (2013). Cdc48/p97 promotes degradation of aberrant nascent polypeptides bound to the ribosome. Elife 2:e00308. doi: 10.7554/eLife.00308
Wang, J., Satoh, M., Pierani, A., Schmitt, J., Chou, C. H., Stunnenberg, H. G., et al. (1994). Assembly and DNA binding of recombinant $\mathrm{Ku}$ (p70/p80) autoantigen defined by a novel monoclonal antibody specific for $\mathrm{p} 70 / \mathrm{p} 80$ heterodimers. J. Cell Sci. 107(Pt 11), 3223-3233.

Wang, Y., Satoh, A., Warren, G., and Meyer, H. H. (2004). VCIP135 acts as a deubiquitinating enzyme during p97-p47-mediated reassembly of mitotic Golgi fragments. J. Cell Biol. 164, 973-978. doi: 10.1083/jcb.200401010

Wilcox, A. J., and Laney, J. D. (2009). A ubiquitin-selective AAA-ATPase mediates transcriptional switching by remodelling a repressor-promoter DNA complex. Nat. Cell Biol. 11, 1481-1486. doi: 10.1038/ncb1997

Wilson, M. D., Harreman, M., and Svejstrup, J. Q. (2013). Ubiquitylation and degradation of elongating RNA polymerase II: the last resort. Biochim. Biophys. Acta 1829, 151-157. doi: 10.1016/j.bbagrm.2012.08.002

Wojcik, C., Yano, M., and Demartino, G. N. (2004). RNA interference of valosin-containing protein $(\mathrm{VCP} / \mathrm{p} 97)$ reveals multiple cellular roles linked to ubiquitin/proteasome-dependent proteolysis. J. Cell Sci. 117, 281-292. doi: $10.1242 /$ jcs.00841

Xouri, G., Squire, A., Dimaki, M., Geverts, B., Verveer, P. J., Taraviras, S., et al. (2007). Cdt1 associates dynamically with chromatin throughout G1 and recruits Geminin onto chromatin. EMBO J. 26, 1303-1314. doi: 10.1038/sj.emboj.7601597

Ye, Y., Meyer, H. H., and Rapoport, T. A. (2001). The AAA ATPase Cdc48/p97 and its partners transport proteins from the ER into the cytosol. Nature 414, 652-656. doi: 10.1038/414652a

Zhang, X., Gui, L., Zhang, X., Bulfer, S. L., Sanghez, V., Wong, D. E., et al. (2015). Altered cofactor regulation with disease-associated p97/VCP mutations. Proc. Natl. Acad. Sci. U.S.A. 112, E1705-E1714. doi: 10.1073/pnas.1418 820112

Zhong, W., Feng, H., Santiago, F. E., and Kipreos, E. T. (2003). CUL-4 ubiquitin ligase maintains genome stability by restraining DNA-replication licensing. Nature 423, 885-889. doi: 10.1038/nature01747

Conflict of Interest Statement: The authors declare that the research was conducted in the absence of any commercial or financial relationships that could be construed as a potential conflict of interest.

Copyright (C) 2016 Franz, Ackermann and Hoppe. This is an open-access article distributed under the terms of the Creative Commons Attribution License (CC BY). The use, distribution or reproduction in other forums is permitted, provided the original author(s) or licensor are credited and that the original publication in this journal is cited, in accordance with accepted academic practice. No use, distribution or reproduction is permitted which does not comply with these terms. 